\title{
Noise environments in nursing homes: an overview of the literature and a case study in Flanders with quantitative and qualitative methods*
}

Pieter THOMAS, Francesco ALETTA ${ }^{b}$, Karlo FILIPANa, Tara VANDER MYNSBRUGGE ${ }^{c}$, Lieven DE GEETERE $^{d}$, Arne DIJCKMANS ${ }^{d}$, Dick BOTTELDOOREN ${ }^{a}$, Mirko PETROVIC ${ }^{e}$, Dominique VAN DE VELDEc, Patricia DE VRIENDT ${ }^{c}$, Paul DEVOS ${ }^{a}$

\author{
Affiliations: \\ a Department of Information Technology, Ghent University, 9052 Ghent, Belgium \\ ${ }^{b}$ Institute for Environmental Design and Engineering, University College London, WC1HONN London, \\ United Kingdom \\ ${ }^{c}$ Department of Occupational Therapy, Artevelde University College, 9000 Ghent, Belgium \\ d Belgian Building Research Institute, 1000 Brussels, Belgium \\ e Department of Internal Medicine and Paediatrics, Ghent University, 9000 Ghent, Belgium
}

\section{Corresponding author:}

Paul Devos

Postal address: WAVES Research Group - Technology Park 126 - iGent Tower, Zwijnaarde - 9052 Ghent, Belgium

Email: p.devos@ugent.be

*parts of this work have already been presented in: Thomas, P., Aletta, F., Filipan, K., Vander Mynsbrugge, T., De Geetere, L., Dijckmans, A., et al. (2018). Evaluation and improvement of the acoustic comfort in nursing homes: a case study in Flanders, Belgium. Proceedings of the Euronoise 2018 Conference. Heraklion.

\begin{abstract}
As noise is a basic contributor to the evaluation of an environment, the indoor environment of a nursing home (where residents are provided with 24-hour functional support and care) is studied with this focus. General research results, as indicated from a literature review, are limited up till now. Using quantitative and qualitative methods five nursing homes in Flanders were studied before and after acoustic interventions. Sound levels were measured in individual bedrooms, living rooms and corridors to obtain the typical levels during a day. Acoustic intra-room performance parameters (reverberation time) and inter-room performance parameters (airborne noise insulation level and impact noise insulation level) were measured and compared with Belgian target values. The post operam measurements indicated the potential of the acoustic interventions (use of acoustic curtains, wall and ceiling panels, ventilations grills, floating floors) to improve the building performance and the acoustic climate. From a qualitative viewpoint, the thematic analysis of staff response to the acoustic interventions indicated direct positive outcomes (e.g., more pleasant, quieter indoor soundscapes) with both positive and negative outcomes from perceived indirect effects (i.e., non-acoustic factors).
\end{abstract}




\section{INTRODUCTION}

The acoustic environment of care facilities for older adults is receiving increasing attention from both researchers and practitioners because of the importance that ageing-related issues are gaining in our societies and the challenges they pose. Previous studies have focused both on the perception (van den Bosch, Andringa, Başkent, \& Vlaskamp, 2016; van den Bosch, Andringa, Post, Ruijssenaars, \& Vlaskamp, 2018), as well as physical aspects of the acoustic environment of such spaces (Wiratha \& Tsaih, 2015; Thomas, et al., 2018). It is crucial to define the influence of acoustics for the everyday experience of nursing homes (Aletta, et al., 2017a), both for the residents and the staff members, due to the considerable amount of time they spend in these environments (Aletta, et al., 2018a; 2018b; Vander Mynsbrugge, Van de Velde, Aletta, Botteldooren, Devos, \& De Vriendt, 2018). This study is part of a research project, which aims at improving the acoustic environment in nursing homes in Flanders, particularly for people with dementia, and ultimately at providing architects and decision makers with a broad range of possible acoustic solutions for the organization and optimization of new or existing nursing homes.

It is worth highlighting that the definition of nursing homes might vary between countries. For Belgium, this should be generally understood as "public or private facility with a domestic-styled environment that provides 24-hour functional support and care for persons who require assistance and who often have complex health needs and increased vulnerability" (Sanford, et al., 2015). For other countries, a broader definition of long-term care facility (LTCF) for older adults might apply, but in the context of this study, the facilities will be referred to as nursing homes as an equivalent for LTCF.

\subsection{Acoustic requirements in Nursing Homes: Normative context}

In most European countries, acoustic regulations or guidelines exist for residential and nonresidential buildings aiming to provide good acoustic conditions for the residents, employees and users of the buildings. The requirements vary strongly from country to country, but are typically related to airborne and impact sound insulation, reverberation time, traffic noise and service equipment noise. However, not all countries have specific regulations for nursing homes. Standards and legislation in Germany and France for example only mention requirements for rooms in hospitals and sanatoria.

In Belgium, the acoustic requirements for nursing homes are given by the national standards NBN S 01-400 (Bureau of Normalization, 1977) and NBN S 01-401 (Bureau of Normalization, 1987). NBN S 
01-400 provides criteria for the airborne and impact sound insulation between bedrooms and other rooms (corridors, technical rooms, other bedrooms, service rooms, etc.) in nursing homes. The criteria are given in function of Belgian categories which are not univocally related to the single number ratings $D_{n T, w}$ and $L_{n T, w}^{\prime}$ of ISO 717-1 (International Organization for Standardization, 2013a) and ISO 717-2 (International Organization for Standardization, 2013b). For the airborne sound insulation between two bedrooms, between a bedroom and a corridor, and between a bedroom and a living room, a category III is advised, which corresponds on average with a requirement $D_{n T, w}$ $\geq 44 \mathrm{~dB}$. For the impact sound insulation, a category $\mathrm{II}^{\mathrm{a}}$ is advised between these rooms, which corresponds on average with a requirement $L_{n T, w}^{\prime} \leq 61 \mathrm{~dB}$. NBN S 01-401 provides limit values for the sound levels caused by exterior sound sources (traffic, industry) and interior sound sources (neighbours, technical installations). This is particularly meaningful since, from the perceptual point of view, exterior and interior sound sources are likely to lead to different levels of annoyance in spite of their levels (Aletta, et al., 2017a). The maximum allowed A-weighted noise levels in living and resting spaces depend on the outdoor noise class. These standards are currently being revised in view of the present noise exposure as well as to the current desires with respect to acoustic quality, and will be replaced by a third part in the NBN S 01-400 series, prNBN S 01-400-3 (Bureau for Normalization, 2018). The new standard will give requirements in function of the single number ratings $D_{A}=D_{n T, w}+C$ for airborne sound insulation and $L_{n T, w}^{\prime}$ for impact sound insulation. Regarding airborne sound insulation, $D_{A} \geq 50 \mathrm{~dB}$ is proposed between residents' rooms and $D_{A} \geq 54 \mathrm{~dB}$ between living rooms and residents' rooms, which is significantly stricter than the current standard. On the other hand, the requirement between corridors and resident's rooms is lowered $\left(D_{A} \geq 38 \mathrm{~dB}\right)$. For impact sound insulation, the requirements stay almost the same between residents' rooms and from corridors to residents' rooms $\left(L_{n T, w}^{\prime} \leq 60 \mathrm{~dB}\right)$, but become more strict from living rooms to residents' rooms $\left(L_{n T, w}^{\prime} \leq 50 \mathrm{~dB}\right)$. Furthermore, requirements will be given for the façade sound insulation, the service equipment noise and the reverberation time $(T)$ in community rooms. While it is not the aim to give a general overview of the acoustical requirements in nursing homes in Europe, it could be useful to compare Belgian requirements with the requirements in some neighbouring countries in Western Europe. It is however not straightforward to compare limit values because different descriptors and single number ratings are used in different countries. The relationship between $R^{\prime}$ and $D_{n T}$ depends for example on the ratio of the volume of the receiving room and the area of the separating wall or floor. The difference will however be limited to $1 \mathrm{~dB}$ for typical residents' rooms in nursing homes. In the Netherlands, a requirement of $R^{\prime}{ }_{w} \geq 52 \mathrm{~dB}$ and 
$L_{n T, w}^{\prime} \leq 59 \mathrm{~dB}$ exist between residents' rooms in healthcare facilities. In Norway, the airborne sound insulation $R^{\prime}{ }_{w}$ in care facilities has to reach $52 \mathrm{~dB}$ between residents' rooms and between a resident room and a common room, and $34 \mathrm{~dB}$ between a resident's rooms and corridors. The normalized impact sound level $L_{n, w}^{\prime}$ must be limited to $58 \mathrm{~dB}$ in residents' rooms from other residents' rooms, common areas and corridors. The general requirements in Switzerland depend on the sound production in the source room and the acoustic sensitivity in the receiving room, which gives e.g. requirements of $D_{i}=D_{n T, w}+C+C_{V} \geq 52 \mathrm{~dB}$ and $L^{\prime}{ }_{\text {tot }}=L^{\prime}{ }_{n T, w}+C_{l}+C_{V} \leq 53 \mathrm{~dB}$ between residents' rooms, where the room volume correction term $C_{v}=0 \mathrm{~dB}$ for room volumes smaller than $200 \mathrm{~m}^{3}$. These examples show that the current requirements in Belgium of 1977 for the airborne sound insulation between residents' rooms in nursing homes are low, while the new proposed requirements are in line with those of other European countries.

\subsection{Recent trends in soundscape research for nursing homes}

A commonly accepted definition of "soundscape" as reported in international standards is that of an "acoustic environment as perceived or experienced and/or understood by a person or people, in context" (International Organization for Standardization, 2014), which sets the focus on the fact that users' perception must be central to the discourse. This approach is gaining momentum in the research panorama both for outdoor and indoor contexts (Aletta \& Astolfi, 2018). For the management of the quality of the acoustic environments in nursing homes it might be particularly relevant, due to the specific implications sounds can have for older adults and/or people with other physical or cognitive impairment (van den Bosch, Andringa, Peterson, Ruijssenaars, \& Vlaskamp, 2016). In her work about soundscape in special needs care, van den Bosch (2015) highlights a number of points researchers and practitioners should pay attention to on this matter. Assuming that the main purpose of nursing homes is providing the best possible care for their residents/patients, the acoustics and the way it is perceived should be carefully considered by the management as the negative effects of bad acoustics can be expected to give stronger effects in people with specific cognitive impairments. On the other hand, van den Bosch argues that research in nursing homes (compared to other conventional care facilities) could provide an opportunity to understand more basic human sound perception mechanisms, as cognitively impaired older adults are less affected by higher cognitive processing of auditory events (van den Bosch, 2015; van den Bosch, Andringa, Başkent, \& Vlaskamp, 2016). 
Other researchers are also exploring new paths to put forward the management and design of soundscapes in nursing homes. Design strategies and practical insights for sound-based technologies in the context of dementia care are being considered in a number of projects and initiative worldwide. Devos et al. (2018) carried out a set of co-creation sessions with staff and family members of residents in nursing homes to manage the acoustic environments that residents would be exposed to. The sessions resulted in proposals for soundscape daily patterns, with alternation of existing sounds, added sounds and silence, which was delivered via a network of loudspeakers in bedrooms and living rooms. Work by the same authors subsequently highlighted that temporal patterns are indeed an important element to consider when "designing a soundscape" for people with dementia in nursing homes to exploit its restorative potential for the residents (Devos et al., 2019). Houben et al. (2019) organised three workshops in nursing homes to explore personal experiences evoked by soundscapes for people in early stages of dementia, using a device developed for the purpose ("dementia soundboard"), and to provide insights into how everyday sounds triggered personal associations, memories of the past, and emotional responses. However, sometimes these soundscape studies are not informed by proper acoustic measurements campaigns carried out in context, and/or make limited use of related room and building acoustics data. One of the aims of this study is indeed to overcome this methodological limitation. In general, compared with other possible environmental factors supporting "healing spaces" (e.g., light, smell, temperature), the research attention given to soundscapes has been limited in nursing homes.

\subsection{Overview and research context of the AcustiCare project}

The present study was conducted within the AcustiCare project (led by Ghent University and Artevelde University College), which has a focus on the group of older people with dementia living in nursing homes and experiencing behavioural and psychological symptoms of dementia (BPSD). Dementia is a broad term; persons with dementia (PwD) experience a wide range of symptoms including decline in memory and/or other cognitive skills, which are severe enough to reduce a person's ability to perform everyday activities. The presence of BPSD can be typically observed in more severe stages of dementia. BPSD are considered as a characteristic of dementia but it is also known that the environment, and consequently the acoustic environment, serves as a trigger for BPSD. BPSD have a great impact on the quality of life of persons with dementia and their social contacts such as family and friends, but also on the health professionals working with persons with dementia, and consequently also on the quality of work of those professionals. While no specific 
lower or upper age limit was set for residents of the nursing homes to be included in the project, it seems fair to assume the concept of "older adult" (ca. 60 years or older) would apply in any case. The project has four overarching goals, which it aims to achieve by exploiting the potential of acoustic and soundscape design; namely: (1) increasing the quality of life of the persons with dementia in the nursing homes; (2) reducing the insurgence of BPSD; (3) reducing the use of psychoactive drugs; and (4) reducing the stress of care staff.

Five different nursing homes, partners of the project consortium, were selected as case study. The selection consisted of a mix of both recently built facilities as well as renovated facilities dating from the end of the $20^{\text {th }}$ century. Other partners of the project included acoustic consultants, manufacturers of acoustic materials and solutions, architectural and design firms and a national agency for the building industry (http://www.acusticare.be/).

In the context of this project, the approach to achieve the aforementioned general goals was twofold: on one hand it was decided to deploy a number of technical solutions that would enhance the objective acoustic comfort (in terms of sound insulation and room acoustics performance of the facilities); on the other hand, a number of active soundscape design interventions were carried out, but these are not within the scope of this paper and have been considered in other publications (Aletta, et al., 2017a; Devos, et al., 2018).

\subsection{Objectives}

This study aimed at making a demonstration of the improvements that can be achieved in nursing homes for the acoustics of such spaces, and assessing their effectiveness both in terms of objective measures and in terms of "perceived improvement", through analysis of the feedback gathered from staff members immediately after the interventions, thus combining a quantitative and qualitative methodological approach. Research on the acoustics of nursing homes has been limited so far, and for this reason a search of previous studies in the literature and their main results was also considered, to provide some context and background for this study. Thus, in Section 2, a smallscale systematic review of the literature is presented to see what studies performed acoustic interventions in care facilities for older adults and monitored the acoustic environment in the ante and post operam conditions. In Section 3, the AcustiCare project and its case study with five nursing homes is briefly introduced and their current situation in terms of acoustic comfort is considered. The acoustic interventions are described and objective improvements reported. Subsequently, in Section 4 the methodology for gathering staff feedback on the acoustic intervention and its main 
outcomes are reported. In Section 5 the outcomes of the literature review are discussed, as well as the effectiveness of the acoustic interventions of the case study, both objectively measured and perceived by staff.

\section{REVIEW OF THE LITERATURE ABOUT ACOUSTIC MEASUREMENTS IN NURSING HOMES}

While the acoustics of hospitals and other critical care units (e.g., intensive care units, prenatal care units, etc.) has received considerable research attention (see, for instance: Xie, Kang, \& Mills, 2009; Xie \& Kang, 2012), fewer studies have focused on the specific context of nursing homes, in spite of the growing relevance of these care settings in our societies (van den Bosch, 2015).

Considering the descriptive aims of the current paper, there was no pre-defined protocol registration. The basic process and data extraction forms were agreed upon at the beginning of the review work. The study was performed and reported in accordance with the PRISMA guidelines for systematic reviews (Liberati, et al., 2009). The overall aim was to gather information about studies that would consider any type of room and building acoustics measurements in care facilities for older adults.

\subsection{Search strategy, eligibility criteria and data extraction}

Studies were selected if they collected data in care facilities for older adults about acoustic metrics related to sound quality and acoustic comfort; within the framework of this review, these metrics would include: background noise levels (e.g., equivalent continuous sound pressure levels, $N$ percent exceedance levels, etc.), room acoustic parameters (e.g., reverberation time, speech transmission index, clarity, etc.) sound insulation (either airborne, impact or façade insulation) parameters (e.g., standardized level difference, standardized impact sound pressure level, etc.). The specific inclusion criteria for the studies were: (1) including at least one measurement of sound quality or acoustic comfort metrics as per the following international standards: ISO 1996-1:2016 (International Organization for Standardization, 2016) ISO 16283-1:2014/Amd.1:2017 (International Organization for Standardization, 2017) ISO 16283-2:2018 (International Organization for Standardization, 2018) ISO 16283-3:2016 (International Organization for Standardization, 2016) ISO 3382-2:2008 Acoustics (International Organization for Standardization, 2008); (2) having the measurements focus on care facilities dedicated to older adults (nursing homes or any other geriatric department); (3) being peer-reviewed journal articles published in English. 
Studies were identified by searching Scopus ${ }^{\circledR}$ and PubMed database, by manually scanning the reference lists of retrieved items and through consultation with experts in the field. The following search script was used: (TITLE-ABS-KEY("noise measurement*") OR TITLE-ABS-KEY(acoustic*)) AND (TITLE-ABS-KEY("care facilit*") OR TITLE-ABS-KEY("nursing home*")) AND DOCTYPE(ar). The search was applied between $1^{\text {st }}$ January 1957 and present. The last search was performed on $31^{\text {st }}$ January 2019.

The eligibility assessment of the studies was performed independently in a non-blinded standardized manner by two reviewers; a few disagreements between reviewers about inclusion/exclusion of some items were resolved by consensus. Information was extracted from each included study on: (1) the type of acoustic measurements performed, and the corresponding metrics; (2) the type of care facility where the study was performed; (3) the functional spaces within the care facilities where the measurements were performed (4) the type of intervention (if any) for acoustic correction implemented; (5) the type of monitoring performed, in terms of temporal coverage and resolution; and (6) the main outcomes of the study, in terms of compliance with recommendations and/or effectiveness of the intervention. Considering the unresolvable differences in the metrics and approaches across the selected studies, statistical and quantitative meta-analyses were not possible. Consequently, a qualitative approach to data synthesis was adopted.

\subsection{Results of the literature review}

The search through the two databases and the additional manual search returned 118 results. No duplicates were identified, so the titles and abstracts of the retrieved items were screened and 103 records were excluded because the topic of the paper was not relevant. The full-texts of the remaining 15 papers were accessed and 11 of them were excluded because they failed to meet one or more of the eligibility criteria; the remaining four papers were included in the review. Figure 1 summarises the selection process of the review records. 


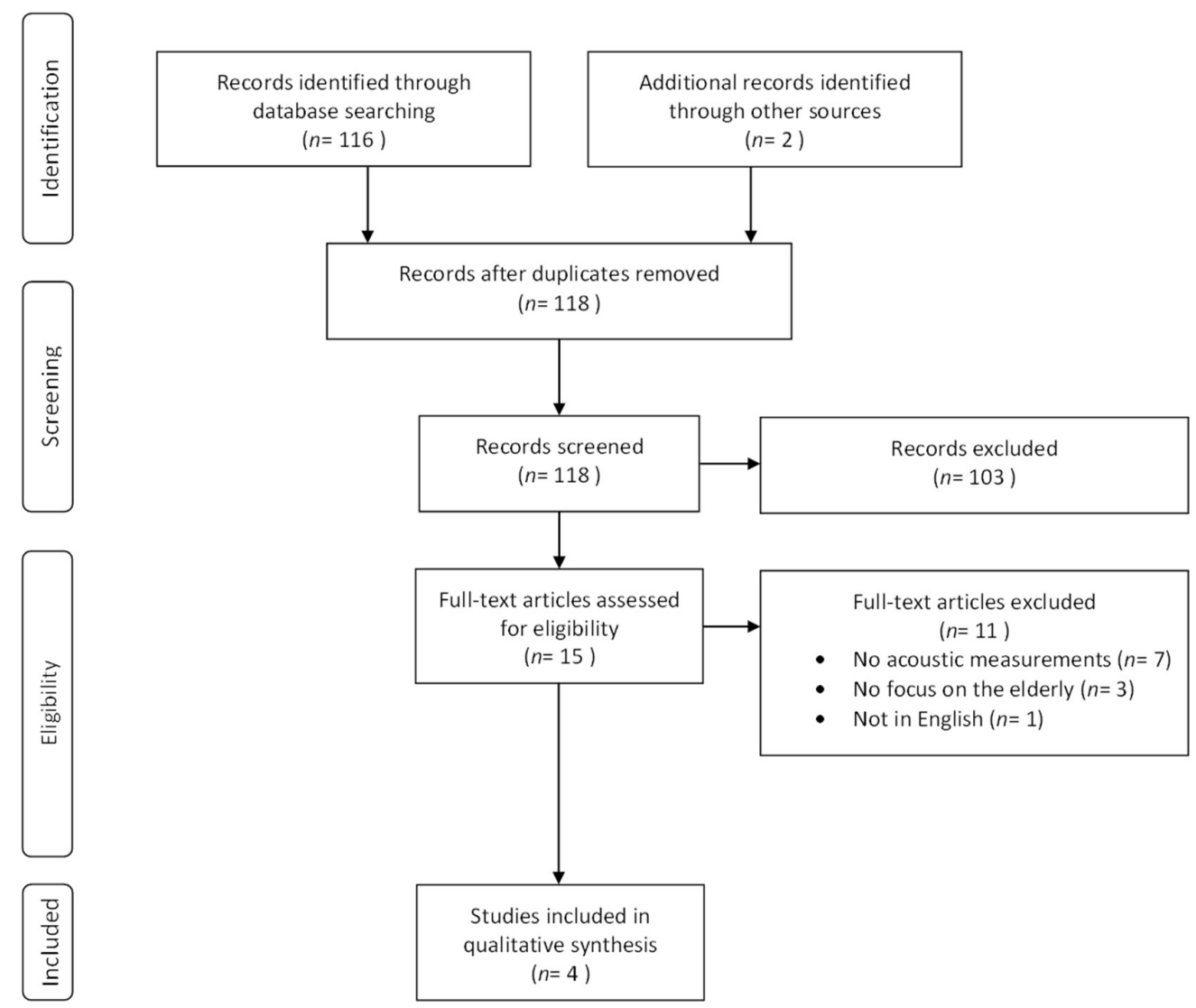

Figure 1 - Flow of information through the different phases of the systematic review.

Table 1 shows the data extracted from the four studies considered in the review, reported according to the chronological order of publication. Two studies (Aletta, et al., 2017b; Peng, Zeng, Zhao, \& Zeng, 2018) included both background noise levels and room acoustics measurements; there was no comparison between different conditions: the main aim was characterising the current acoustical situation of the facilities. The study by Brown et al. (2016) instead did not consider any room or building acoustics parameter, but included sound levels monitoring and an intervention aimed at reducing noise in the care facilities; whilst the study by Jerlehag et al. (2018) included both noise monitoring and reverberation time measurements. These last two studies reported on the effects of the proposed intervention between the ante operam and post operam conditions. The intervention in Brown et al. (2016) consisted of a campaign on noise awareness and the installation of a device for visual feedback on current noise levels. The intervention in Jerlehag et al. (2018) was not actually implemented, but only predicted via acoustic software simulation. 
Table 1 - List of studies included in the systematic review in chronological order of publication.

\begin{tabular}{|c|c|c|c|c|c|c|}
\hline Reference & $\begin{array}{l}\text { Acoustic } \\
\text { metrics } \\
\text { measuremen } \\
\text { t }\end{array}$ & Facility & $\begin{array}{l}\text { Monitored } \\
\text { spaces }\end{array}$ & Intervention & $\begin{array}{l}\text { Type of } \\
\text { monitoring }\end{array}$ & $\begin{array}{l}\text { Main } \\
\text { outcome(s) }\end{array}$ \\
\hline $\begin{array}{l}\text { Brown et al. } \\
2016\end{array}$ & $L_{\text {eq- } 5 \min }$ & $\begin{array}{l}\text { Hospital } \\
\text { (geriatric } \\
\text { ward) }\end{array}$ & Shared areas & $\begin{array}{l}\text { Visual feedback } \\
\text { on noise levels, } \\
\text { awareness } \\
\text { campaign }\end{array}$ & $\begin{array}{l}\text { Three times per } \\
\text { day (quasi- } \\
\text { daily) over a } \\
\text { period of nine } \\
\text { months }\end{array}$ & $\begin{array}{l}\text { Noise levels } \\
\text { were reduced } \\
\text { from } 62 \text { to } 53 \mathrm{~dB} \\
\text { after the } \\
\text { intervention }\end{array}$ \\
\hline $\begin{array}{l}\text { Aletta et al. } \\
2017 b\end{array}$ & $L_{\text {Aeq-15min, }}, T$ & $\begin{array}{l}\text { Nursing } \\
\text { Home }\end{array}$ & Living rooms & $\begin{array}{l}\mathrm{n} / \mathrm{a} \text { - only } \\
\text { monitoring }\end{array}$ & $\begin{array}{l}\text { 24-hour } \\
\text { monitoring for } \\
\text { one week }\end{array}$ & $\begin{array}{l}\text { Noise levels } \\
\text { ranged between } \\
54.6 \text { and } 64.9 \mathrm{~dB} \\
\text { and } \\
\text { reverberation } \\
\text { times between } \\
0.36 \text { and } 1.58 \mathrm{~s}\end{array}$ \\
\hline $\begin{array}{l}\text { Jerlehag et } \\
\text { al. } 2018\end{array}$ & $\begin{array}{l}L_{\text {Aeq-1min }}, \\
L_{\text {Afmax }}, T\end{array}$ & $\begin{array}{l}\text { Hospital } \\
\text { (geriatric } \\
\text { ward) }\end{array}$ & Patient rooms & $\begin{array}{l}\text { software } \\
\text { simulated: } \\
\text { absorbing ceilings }\end{array}$ & $\begin{array}{l}\text { 24-hour } \\
\text { monitoring }\end{array}$ & $\begin{array}{l}\text { Noise levels } \\
\text { ranged between } \\
58.3 \text { to } 64.5 \mathrm{~dB} \\
\end{array}$ \\
\hline $\begin{array}{l}\text { Peng et al. } \\
2018\end{array}$ & $\begin{array}{l}L_{\text {Aeq-day, }} L_{\text {Aeq- }} \\
\text { night, } E D T, T, \\
C_{50}, S T I\end{array}$ & $\begin{array}{l}\text { Nursing } \\
\text { Home }\end{array}$ & $\begin{array}{l}\text { Living rooms, } \\
\text { Dining rooms, } \\
\text { Patient rooms }\end{array}$ & $\begin{array}{l}\text { n/a - only } \\
\text { monitoring }\end{array}$ & $\begin{array}{l}\text { Single day-long } \\
\text { measurement } \\
\text { session }\end{array}$ & $\begin{array}{l}\text { Noise levels } \\
\text { ranged between } \\
26.8 \text { to } 67.2 \mathrm{~dB} \\
\text { and } \\
\text { reverberation } \\
\text { times between } \\
0.36 \text { and } 1.86 \mathrm{~s}\end{array}$ \\
\hline
\end{tabular}

Brown et al. (2016) monitored equivalent continuous sound levels in a mental health ward for older adults at East London NHS Foundation Trust, in UK. This study included an intervention that did not include any specific noise control engineering solution, but was rather aimed at inducing staff behavioural changes through an awareness campaign about the positive effects of reducing noise. Staff meetings were held about quality improvement tools and methods to enable better engagement by all ward staff for the project. A poster was developed and placed in the ward to remind staff, patients, and carers of the benefit of reducing noise levels. Furthermore a visual reminder was installed consisting of a sound level meter associated to a red-yellow-green light system that would be activated depending on the sound levels (i.e., visual feedback). For the duration of the project (ante and post operam conditions), staff were instructed to download a calibrated smartphone sound level meter application and register sound levels at specific times and locations of maximal noise (such as mealtimes and in shared areas) over a period of five minutes, three times a day, for a period of nine months. The authors observed that sound levels reduced from $62 \mathrm{~dB}$ to $53 \mathrm{~dB}$, after the installation of the poster and the visual feedback system.

The study by Aletta et al. (2017b) was performed within the same project of the present work. Sensor nodes were installed in the living rooms, corridors and residents' rooms of five nursing homes in Flanders, Belgium. The nodes continuously measured 1/3-octave band levels during a 
typical week of activity of the nursing homes and the A-weighted sound equivalent levels were then calculated on a 15 -min basis ( Leq-15min $_{\text {}}$ ) for all data available, for each sensor node. The reverberation time $(T)$ was also measured in the living rooms in accordance with the standard ISO 3382-2:2008 (International Organization for Standardization, 2008). The results showed that both median sound levels and reverberation times varied greatly among the nine living rooms, ranging between 54.6 and $64.9 \mathrm{~dB}$ for the former, and between 0.36 and $1.58 \mathrm{~s}$ for the latter.

Jerlehag et al. (2018) measured the background noise and noise sources in the patient rooms of the geriatric ward of a university hospital in Liverpool, in UK. The acoustic measurements were carried out over a 24-h period in five typical rooms (one six-bedded, two four-bedded, and two singlebedded rooms). The A-weighted equivalent $\left(\mathrm{L}_{\mathrm{Aeq}}\right)$ and maximum Fast time-weighted sound pressure levels ( $L_{A F m a x}$ ) were calculated: the overall 24 -hour sound levels in the patient rooms ranged from 58.3 to $64.5 \mathrm{~dB}$. Within this research, the authors developed a case study to explore the effect of installing an absorbing suspended ceiling in the six-bedded room. The measured reverberation time at $1 \mathrm{kHz}$ was $0.68 \mathrm{~s}$. The computer simulations showed that absorptive treatments in the ceiling could lead to significant reductions in reverberation time $(0.33 \mathrm{~s}$, on average) and sound pressure level (2.9 dB, on average).

Peng et al. (2018) monitored the background noise and measured a set of room acoustics parameters in 62 rooms (including living rooms, dining rooms and patient rooms) in 11 different nursing homes in Guangzhou, China. The background noise levels in the 62 rooms ranged from 26.8 to $67.2 \mathrm{dBA}$ (instant measures). The ranges for reverberation times $(T)$, early-to-late sound ratio $\left(\mathrm{C}_{50}\right)$ values, and speech transmission index (STI) values in these rooms were $0.36-1.86 \mathrm{~s},-4.48$ to $9.67 \mathrm{~dB}$ and $0.47-0.81$, accordingly.

\section{CASE STUDY OF THE ACUSTICARE PROJECT}

The following sections report on the case study developed in the five nursing homes of the AcustiCare project. In the context of this study the five facilities were coded as: LH, SJ, SV, SP, and $\mathrm{VH}$. The building characteristics and architectural features of the facilities in terms of materials and technology varied considerably among the five sites with structures in concrete built (or renovated) across a relatively long span of time, ranging from the early 1980 s to late 2010 s. Typically in multistorey facilities, the departments of interests for this project, hosting people with dementia, were allocated on different floors of the buildings (ground floor in three cases, upper floors in the remaining two). On the other hand, the layout of the departments would typically see a living room 
with a kitchen and a care staff space/office connected to a corridor with bedrooms for the residents on the side(s).

Section 3.1 reports the outcome of the ante operam measurements campaign. This consisted of both a medium-term monitoring of the sound pressure levels in different spaces of the facilities, and an assessment of the building acoustics performance in terms of reverberation time and sound insulation parameters. Subsequently, Section 3.2 describes what kind of interventions were implemented for acoustic correction and provides an overview of the enhancements achieved between the ante and post operam conditions.

\subsection{Characterization of the acoustics in the nursing homes prior to interventions}

In order to characterise the overall acoustic environment of everyday life spaces in the nursing homes cost-effective sensor nodes were installed in several spaces to monitor noise levels. Three types of spaces were considered: corridors (i.e. transition and functional spaces, as well as junction spaces between these and the living rooms), living rooms (i.e. common areas where groups of residents spend most of their day time and often have breakfast, lunches and dinners in) and bedrooms (i.e. individual rooms where residents stay alone or sometimes in couple, typically connected to the living rooms via corridors). Five nodes for each of the three space types above were considered for this study ( 15 nodes in total) with three nodes in each of the five nursing homes. Nodes were installed far from specific noise sources (e.g. equipment, doors, etc.) to avoid misrepresentation of the noise levels, but close enough to be representative of the activities typically taking place in such spaces. The nodes measured 1/3-octave band levels continuously (125 ms temporal resolution). The monitoring intervals considered were from 07:00 am of a Monday to 07:00 am of a Friday, during a typical week of activity in the nursing homes, between December 2016 and February 2017. The rationale for monitoring weekdays only was that during weekends the functioning of the nursing homes does not always follow the same pattern: visitors for residents are more frequent, exceptional activities are more likely to happen, changes in staff members attendance may occur. Under such circumstances sound pressure levels (SPLs) trends might express different acoustic climates, which might not necessarily be representative of normal working conditions, and most crucially may be out of the control possibilities of the nursing homes management. Data were sent over the internet to the Ghent University server infrastructure. The A-weighted sound equivalent levels were then calculated on a 15 -minute basis ( $\left.L_{\text {Aeq-15min }}\right)$ for the reference intervals, for each sensor node (Aletta, et al., 2017a; 2017b). The A-weighted sound 
equivalent levels were then averaged according to the types of spaces and to the nursing homes. Figure 2 shows the sound levels as a function of time, aggregated for nursing homes and days of monitoring. In terms of daily pattern it can be observed that during the nights, levels are higher in the bedrooms and lower in the corridors and the living rooms: bedrooms are indeed occupied, living rooms are empty and there could be some staff occasionally moving in the corridors (e.g. night shift, care to residents). For most parts of the day, the levels in the bedrooms are lower because residents (and staff) are typically present in the living rooms; the levels of the corridors are lower than the living rooms, but follow more or less the same pattern because those spaces are often connected. After dinner, the levels in the living rooms drop because residents go back to their bedrooms and there is more activity in the corridors because of the shift-change and staff preparing for the night.
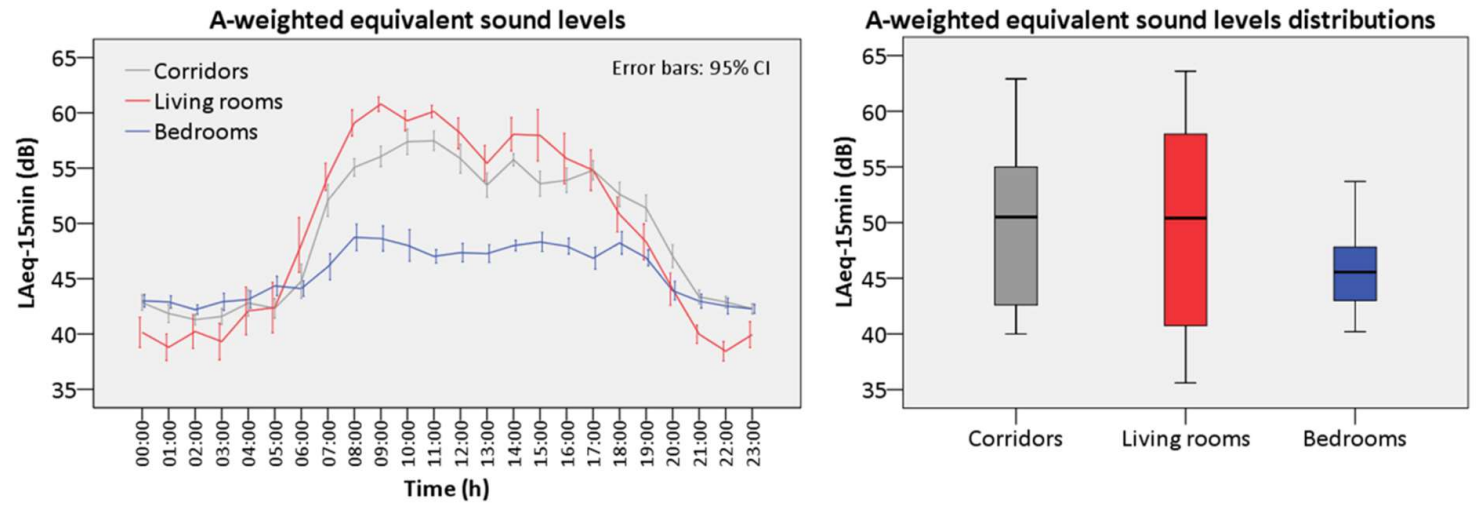

Figure 2 - Daily patterns of the sound levels aggregated across nursing homes for the different types of spaces (left) and their overall distributions (right)

In Figure 3, levels are presented for each nursing homes, aggregated for times and types of space. It can be observed that two nursing homes are slightly noisier than the others, which instead have median levels ranging between $45 \mathrm{~dB}$ and $50 \mathrm{~dB}$. Such differences are likely to depend on the specific sound sources present in each nursing home and possibly different behaviours of both staff and residents. 


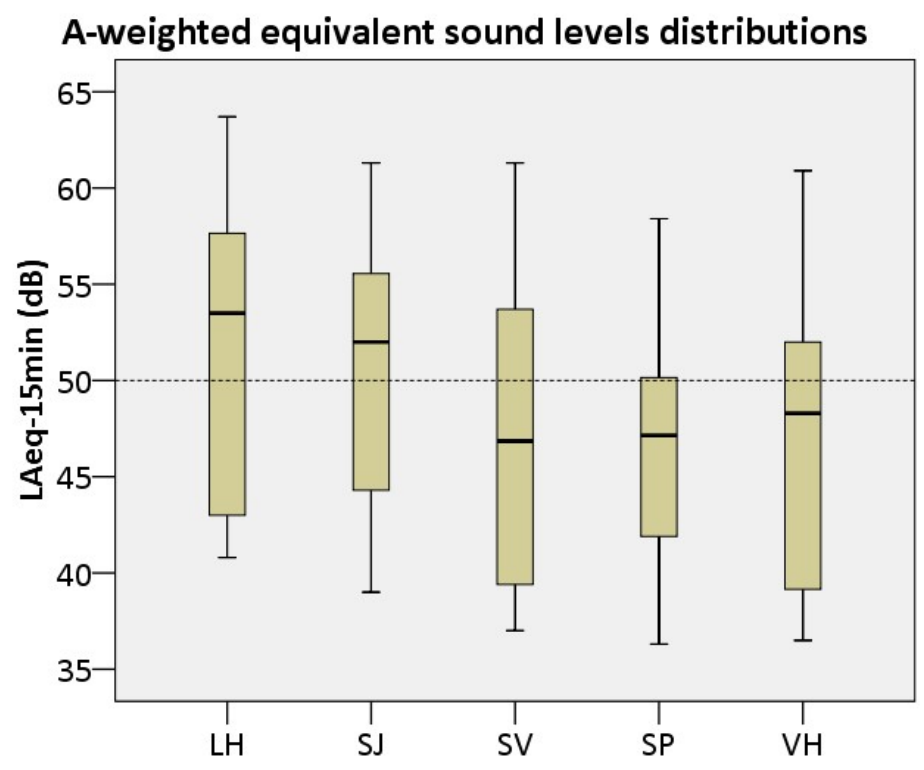

Figure 3 - Distributions of sound levels in the five nursing homes of the project aggregated over time and types of space; the median levels are represented by the black ticks in the boxes indicating also the $2^{\text {nd }}$ and $3^{\text {rd }}$ quartiles.

Additionally to determining typical sound pressure levels, a set of measurement campaigns was organized with the support of different acoustic consultants (AcustiCare project partners) to characterise the building acoustic performance of the different nursing homes. Airborne noise insulation was measured in terms of standardized level difference $D_{n T}$ (International Organization for Standardization, 2017), between living room and residents' rooms (5 cases), corridor and residents' rooms (12 cases), between residents' rooms (15 cases for rooms on the same floor and 3 cases for rooms vertically stacked). Impact noise insulation was measured in terms of standardized impact sound pressure level $L_{n T}^{\prime}$ (International Organization for Standardization, 2018) between living room and residents' rooms (3 cases), from corridor to residents' rooms ( 9 cases) and between residents' rooms (12 cases for rooms on the same floor and 3 cases for rooms vertically stacked). Further to these measures, which mainly describe sound transmission and propagation through building elements, the reverberation time was measured as a proxy for the acoustic comfort inside the room. Reverberation time values were determined according to (International Organization for Standardization, 2008) in 17 different residents' rooms, 11 living rooms and 4 corridors. To enable rating based on a single-value parameter, $D_{n T}, L_{n T}^{\prime}$ values are converted to their weighted equivalent, $D_{n T, w}\left(C, C_{t r}\right)$ and $L_{n T, w}^{\prime}\left(C_{i}\right)$ (International Organization for Standardization, 2013a; International Organization for Standardization, 2013b) while $T_{500 \mathrm{~Hz}-2 \mathrm{kHz}}$ is used as a representative indicator for the reverberation time. A summary of the results is given in Figure 4 and average values with 
standard deviations are given in Table 2 and Table 3. The current Belgian target values are indicated as well and are stated as $D_{n T, w} \geq 44 \mathrm{~dB}$ and $L_{n T, w}^{\prime} \leq 61 \mathrm{~dB}$. These target values, defined by NBN S 01400 , are currently under revision and there is a broad consensus in the national sector that they should be regarded as minimal target values for normal acoustic comfort. The target value $T_{500 \mathrm{~Hz}}$ $2 \mathrm{kHz}=0.8 \mathrm{~s}$ for living rooms and $T_{500 \mathrm{~Hz}-2 \mathrm{kHz}}=1.2 \mathrm{~s}$ for corridors is based on values proposed in (Flemish Government, 2010). In the current draft of prNBN S 01-400-3, no specific reverberation time requirements are given for corridors. For community rooms, a value $T_{\text {nom }}<1 \mathrm{~s}$ is proposed, with $T_{\text {nom }}$ defined as the average reverberation time in the octave bands of $500 \mathrm{~Hz}, 1000 \mathrm{~Hz}$ and $2000 \mathrm{~Hz}$, obtained using the procedures of (International Organization for Standardization, 2008).

Table 2 - Average acoustic performance in nursing homes: mean values and standard deviations of $D_{n T, w}\left(C, C_{t r}\right)$ and $L_{n T, w}^{\prime}\left(C_{i}\right)$

\begin{tabular}{lllll}
\hline & $\mu_{D n T, w}(\mu C, \mu C t r)$ & $\sigma_{D n T, w}$ & $\mu_{\mathrm{L}^{\prime} \mathrm{nT}, \mathrm{w}(\mu \mathrm{C})}$ & $\sigma_{\mathrm{L}^{\prime} n T, w}$ \\
\hline Residents' room to room (same floor) & $49.7(-1.3 ;-4.3) \mathrm{dB}$ & $6.3 \mathrm{~dB}$ & $56.7(-6.6) \mathrm{dB}$ & $6.8 \mathrm{~dB}$ \\
Residents' room to room (different floor) & $53.3(-1.0 ;-5.3) \mathrm{dB}$ & $3.8 \mathrm{~dB}$ & $63.7(-3.3) \mathrm{dB}$ & $2.1 \mathrm{~dB}$ \\
Corridor to residents' rooms & $27.3(-0.8 ;-0.3) \mathrm{dB}$ & $3.0 \mathrm{~dB}$ & $66.9(-9.2) \mathrm{dB}$ & $3.0 \mathrm{~dB}$ \\
Living room to residents' rooms & $36.6(-1.2 ;-1.2) \mathrm{dB}$ & $12.0 \mathrm{~dB}$ & $59.3(-10.7) \mathrm{dB}$ & $1.2 \mathrm{~dB}$ \\
\hline
\end{tabular}

Table 3 - Average acoustic performance in nursing homes: mean values and standard deviation of $T_{20 ; 500 \mathrm{~Hz}-2 \mathrm{kHz}}$

\begin{tabular}{lll}
\hline & $\mu_{T 20 ; 50 O \mathrm{~Hz}-2 \mathrm{kHz}}$ & $\sigma_{T 20 ; 500 \mathrm{~Hz}-2 \mathrm{kHz}}$ \\
\hline Residents' rooms & $0.55 \mathrm{~s}$ & $0.19 \mathrm{~s}$ \\
Corridors & $1.09 \mathrm{~s}$ & $0.71 \mathrm{~s}$ \\
Living rooms & $0.95 \mathrm{~s}$ & $0.36 \mathrm{~s}$ \\
\hline
\end{tabular}

Figure 4(a) shows that the target value of $D_{n T, w}=44 \mathrm{~dB}$ is fairly met for airborne sound insulation between residents' rooms, with $D_{n T, w}=49.7 \mathrm{~dB}$ on average. In one case the condition is not met due to an acoustic leak originating from piping. In contrast to this, the target for the airborne sound insulation between corridor and residents' rooms is not met. In this case, $D_{n T, w}=27.3 \mathrm{~dB}$ on average. Here, the acoustic performance is mainly determined by the doors, which in most cases have ventilation slits at the bottom and bad acoustic sealing at the sides. The airborne sound insulation between living rooms and residents' rooms depends on the relative location between living room and residents' room. If the living room is a self-contained entity, with doors blocking sound propagation to the corridor, performance similar as between residents' rooms is met. However, if the living room has an open structure, directly connected to the corridor, without any doors to block propagation, a performance similar as from corridor to residents' room is seen. In our study, the latter has been most often encountered. 
Results for $L_{n T, w}^{\prime}$ are shown in Figure 4(b). In most cases the impact noise sound insulation between residents' rooms on the same floor complies with the proposed standard, $L^{\prime}{ }_{n T, w}=56.7 \mathrm{~dB}$ on average. Nevertheless, impact noise insulation for vertically stacked rooms did not meet the target proposal. However, care should be taken to draw general conclusions as only three cases were investigated. Regarding the impact sound insulation between corridor and residents' rooms, measured values were higher than the proposed value in almost every case. On average, we measured $L_{n T, w}^{\prime}=66.9 \mathrm{~dB}$. It should be noted that measurements in this case are not only determined by the performance of the contact noise insulation of the floor, but also by an airborne contribution from the tapping machine due to low $D_{n T}$-values. The impact sound insulation between living rooms and residents' rooms was measured in three cases. All cases complied with the proposed target value.

In Figure $4(\mathrm{c})$ the reverberation time $T_{500 \mathrm{~Hz}-2 \mathrm{kHz}}$ is given. For residents' rooms, no target value was given by the Belgian standard, as acoustics is mainly determined by the furnishing of the room. However, from measurements in 17 residents' rooms, an average $T_{500 \mathrm{~Hz}-2 \mathrm{kHz}}=0.55 \mathrm{~s}$ is found. $T_{500 \mathrm{~Hz}-}$ $2 \mathrm{kHz}$ is lower than $0.8 \mathrm{~s}$ in almost every room. No such conclusion can be drawn for $T_{500 \mathrm{~Hz}-2 \mathrm{kHz}}$ measured in living rooms. In most of the cases the target value is not met and although the average $T_{500 \mathrm{~Hz}-2 \mathrm{kHz}}=0.95 \mathrm{~s}$, a large standard deviation of $0.36 \mathrm{~s}$ is seen, indicating that large differences occur. Lowest values were measured at the smallest living rooms (with absorption present), while highest values were measured in large living rooms with limited absorption. Additionally, measurements of $T_{500 \mathrm{~Hz}-2 \mathrm{kHz}}$ were performed in four corridors. For two corridors results are below the target value of 1.20 s. However, in two other corridors, with acoustically hard materials, this target value is exceeded, and values up to $1.83 \mathrm{~s}$ were measured.
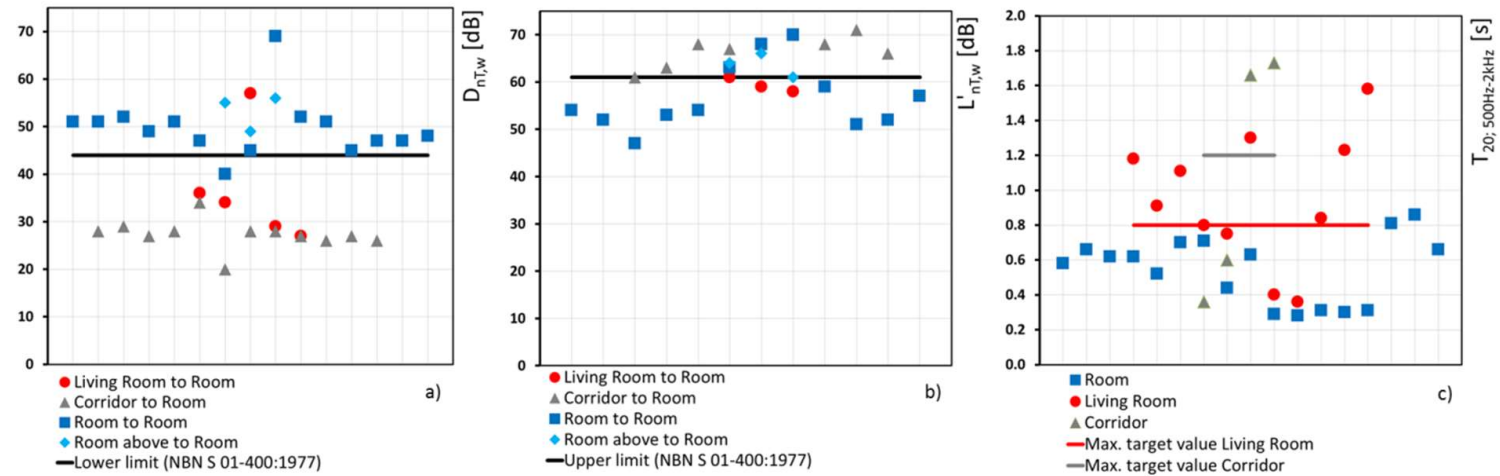

Figure 4 - Building acoustic performance measured in the five nursing homes, ante operam: $D_{n T, w}(\mathrm{a}), L_{n T, w}^{\prime}(\mathrm{b})$, and $T_{500 \mathrm{~Hz}-2 \mathrm{kHz}}(\mathrm{c})$. 


\subsection{Improvements of the acoustic comfort in the nursing homes}

From each of the five nursing homes, a specific case study was selected to deploy an acoustic intervention. In most cases it was opted to improve the situation with the worst acoustic performance. However, the purpose was not the solving of all situations with low-quality acoustic performance, but rather demonstrating a variety of different acoustic solutions to the participating partners of the project. Interventions focused on (1) improving the building performance (reducing noise propagation to residents' rooms) and (2) improving the acoustic climate by reduction of the reverberation time. When reducing the noise propagation to residents' rooms, focus was put on acoustic interventions which reduce the sound propagation from living room and corridor to residents' rooms, rather than between rooms since previous results showed that in most cases (airborne) sound insulation between residents' rooms already complies with the targets defined in the current Belgian standards. First, two interventions were installed that directly improve the noise insulation problem originating from acoustic leaks by the doors. In SV acoustic curtains of ShowTeX were installed near the entrance of the room, creating a small ante-chamber as an extra buffer between corridor and the resident's room (Fig. 5(a)). Installation of this curtain improved the $D_{n T, w^{-}}$ value with $11 \mathrm{~dB}$. In LH, a large ventilation grill in the door of a resident's room was replaced by an acoustic ventilation grill by DOX-Acoustics and absorbing panels (Gyproc) were installed in the corridor leading to the entrance of the room (Fig. 5(b)), accounting for an extra $5 \mathrm{~dB}$ increase of $D_{n T, w}$ in total.

Secondly, interventions were taken to reduce propagation (of noise from living rooms) through corridors to residents' rooms. In SJ absorbing panels were installed by DOX-Acoustics on the walls $\left(2 \mathrm{~m}^{2}\right.$ ) and ceiling (four panels, $2.88 \mathrm{~m}^{2}$ in total) of the $12 \mathrm{~m}$-long corridor (Fig. 5(d)), not only reducing reverberation time $T_{500 \mathrm{~Hz}-2 \mathrm{kHz}}$, but also reducing the propagation of noise by $2.5 \mathrm{dBA}$ on average. In SP, five absorbing panels of Triplaco $\left(5^{*} 5.63 \mathrm{~m}^{2}\right)$ were installed along a $26.5 \mathrm{~m}$-long corridor connecting residents' rooms with two living rooms at each side of the corridor (Fig. 5(c)). Aside from the reduction of $T_{500 \mathrm{~Hz}-2 \mathrm{kHz}}$, an additional decay of $3 \mathrm{dBA}$ was achieved at the end of the corridor. Thirdly, interventions were taken to reduce generation of noise in living rooms and propagation to nearby residents' rooms. As an illustration on how to improve the impact sound insulation, a floating acoustic floor (Moduleo) was installed in $\mathrm{VH}$, on top of the floor of a living room and corridor nearing a resident's room (Fig. 6(a)). A reduction of $L^{\prime}{ }_{n T, w}$ with $12 \mathrm{~dB}$ was achieved. In the same area covered with the acoustic floor, absorbing ceilings (Gyproc) were also installed. The main effect of this intervention was seen for the reverberation time. 

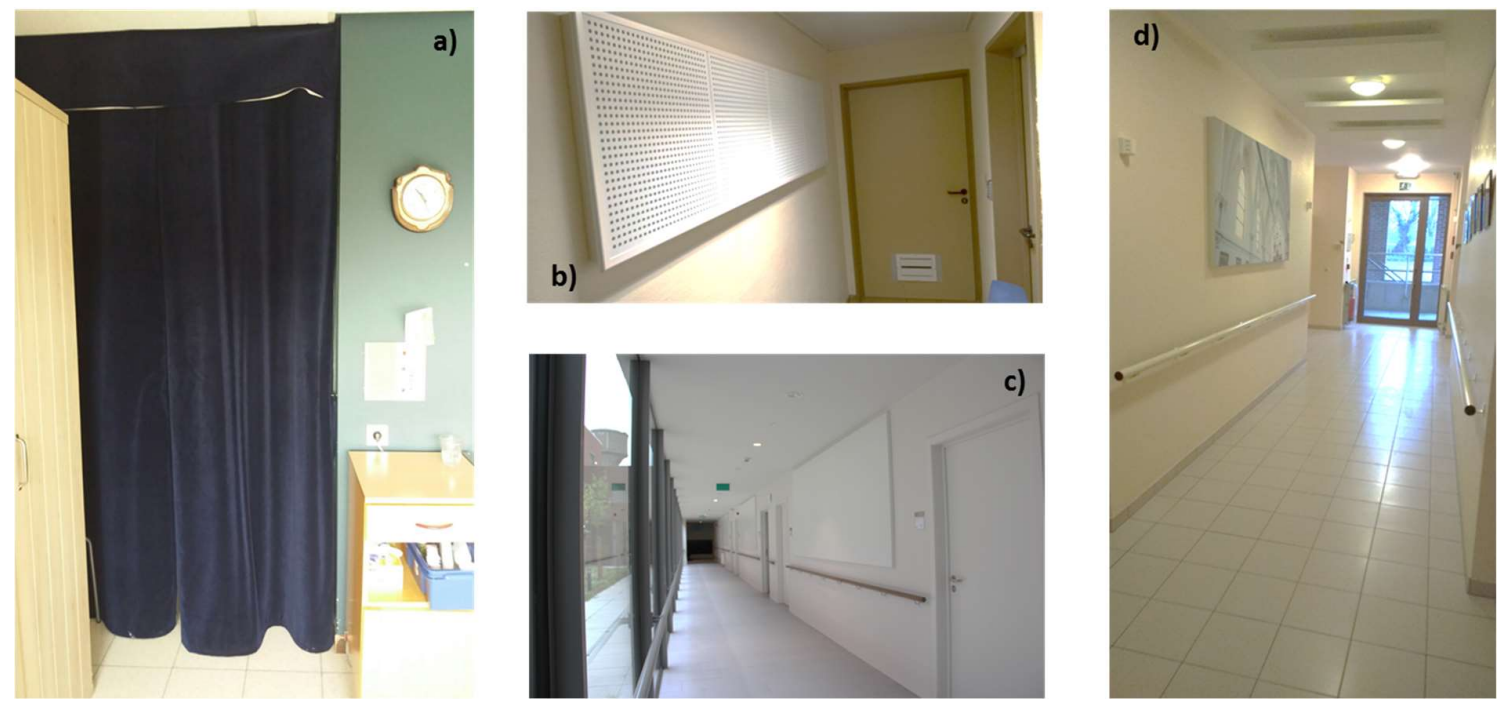

Figure 5-Overview of the acoustic interventions in the residents' rooms and corridors: a) acoustic curtain (ShowTex) in a resident's room in SV; b) acoustic ventilation grill (DOX-Acoustics) and absorbing wall panels (Gyproc) in LH; c) corridor with absorbing wall panels (Triplaco) in SP; corridor with absorbing wall and ceiling panels (DOX-Acoustics) in SJ.
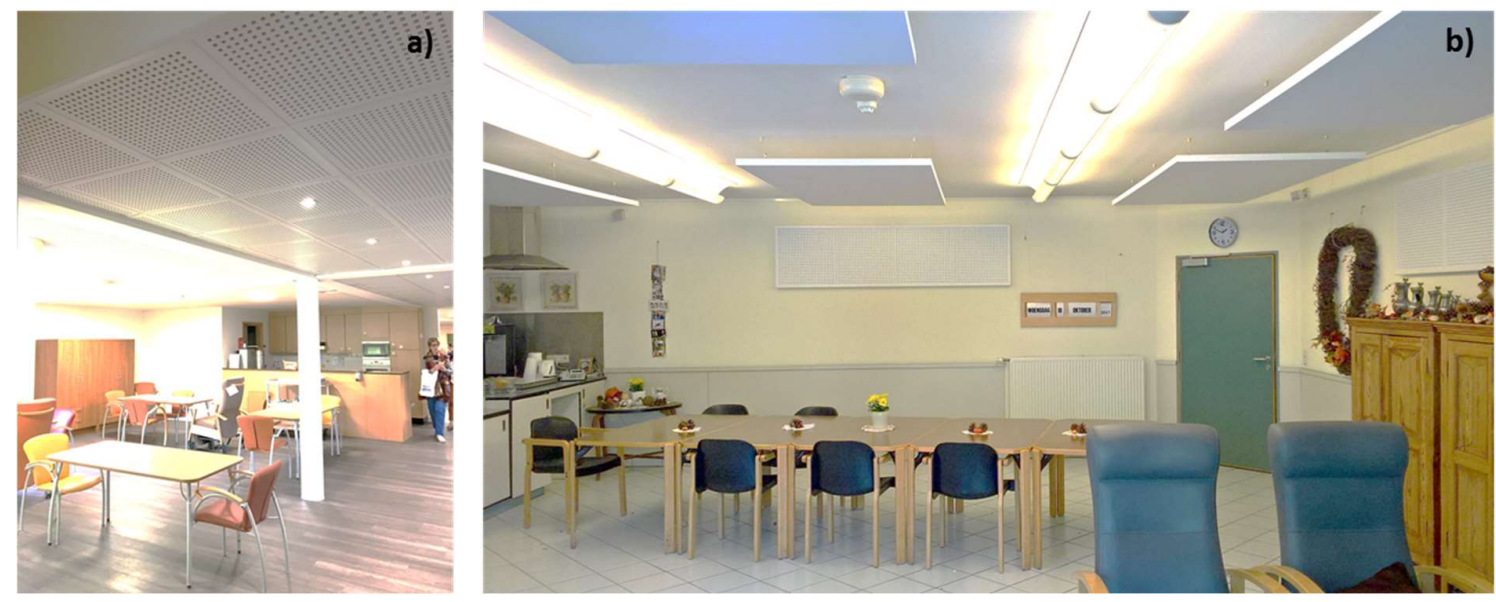

Figure 6 - Overview of the acoustic interventions in the living rooms: a) dining room with absorbing ceiling panels (Gyproc) and acoustic floating floor in $\mathrm{VH}$; b) living room with absorbing ceiling panels (DOX-Acoustics) and wall panels (Gyproc) in LH.

For the improvement of the acoustic climate, i.e. the reverberation time, focus was put on the living rooms (target value for $T_{500 \mathrm{~Hz}-2 \mathrm{kHz}}=0.8 \mathrm{~s}$ ) and corridors (target value for $T_{500 \mathrm{~Hz}-2 \mathrm{kHz}}=1.2 \mathrm{~s}$ ). For residents' rooms previous measurements showed acceptable typical values for $T_{500 \mathrm{~Hz}-2 \mathrm{kHz}}(0.55 \mathrm{~s}$ on average) and therefore little correction is needed. In VH a living room (consisting of two parts - a dining area and seating area) with a hard plaster ceiling was equipped with $110 \mathrm{~m}^{2}$ of acoustic gypsum tiles from Gyproc (in addition to the floating acoustic floor - of Moduleo) (Fig. 5(a)). In the dining area a reduction of $T_{500 \mathrm{~Hz}-2 \mathrm{kHz}}$ from $1.18 \mathrm{~s}$ to $0.91 \mathrm{~s}$ was achieved - still slightly higher than the 
target value of $0.8 \mathrm{~s}$, while in the seating area a reduction from $0.91 \mathrm{~s}$ to $0.39 \mathrm{~s}$ was obtained. A second living room in LH was treated with six absorbing ceiling panels by DOX-Acoustics $\left(14.4 \mathrm{~m}^{2}\right.$ in total) and $1.44 \mathrm{~m}^{2}$ of absorbing wall elements of Gyproc (Fig. $6\left(\right.$ b)). Here, a reduction in $T_{500 \mathrm{~Hz}-2 \mathrm{kHz}}$ from $1.3 \mathrm{~s}$ to $0.57 \mathrm{~s}$ was found. Furthermore, two corridors, one in SJ (absorbing panels were installed by DOX-Acoustics) and one in SP (five absorbing panels of Triplaco) have been selected (see above). In SJ the reverberation time was reduced from $T_{500 \mathrm{~Hz}-2 \mathrm{kHz}}=1.66 \mathrm{~s} T_{500 \mathrm{~Hz}-2 \mathrm{kHz}}=0.97 \mathrm{~s}$, while in SP a reduction from $T_{500 \mathrm{~Hz}-2 \mathrm{kHz}}=1.73 \mathrm{~s}$ to $T_{500 \mathrm{~Hz}-2 \mathrm{kHz}}=0.97 \mathrm{~s}$ was seen. Table 4 shows a summary of the acoustic improvements for the different parameters under investigation.

In order to gather further insights into possible medium-term effects of the acoustic treatments on the overall acoustic environment, similar sensor nodes as in Section 3.1 were installed to monitor noise levels after the installations. Two cases were selected as examples: the corridor-living room connection in VH (where acoustic floor and absorbing ceilings have been installed in the living room area) and the bedroom in SV (where an acoustic curtain has been installed close to the door to shield the bed area from the adjacent living room). The monitoring intervals ranged from 07:00 am of a Monday to 07:00 am of a Friday, during a typical week of activity in the nursing homes, between November and December 2017, in order to match a similar monitoring interval as per the preintervention situation. Considering the 15 -minute $L_{\text {Aeq }}$-values calculated from the sensor nodes, statistical tests were performed to analyse potential differences between the ante and post conditions, for both the corridor-living room and bedroom cases. Thus, "acoustic treatment" was defined as a two-level categorical variable (i.e. ante and post).

Table 4 - Summary of the acoustic improvements

\begin{tabular}{lrr}
\hline$D_{n T, w}\left(C ; C_{t r}\right)$ & ante operam & post operam \\
\hline Acoustic curtains (resident's room - SV) & $29(-2 ;-1) \mathrm{dB}$ & $40(-1 ;-4) \mathrm{dB}$ \\
Acoustic ventilation grill + wall panels (resident's room - LH) & $20(-1 ;-1) \mathrm{dB}$ & $25(0 ;-1) \mathrm{dB}$ \\
\hline$L_{n T, w}\left(C_{i}\right)$ & & \\
\hline Floating floor (living room - VH) & $61(-13) \mathrm{dB}$ & $48(-3) \mathrm{dB}$ \\
Floating floor (dining room - VH) & $59(-11) \mathrm{dB}$ & $47(-4) \mathrm{dB}$ \\
\hline$T_{20 ; 500 \mathrm{~Hz}-2 \mathrm{kHz}}$ & & $0.97 \mathrm{~s}$ \\
\hline Wall/ceiling panels (corridor - SJ) & $1.66 \mathrm{~s}$ & $0.97 \mathrm{~s}$ \\
Wall panels (corridor - SP) & $1.73 \mathrm{~s}$ & $0.39 \mathrm{~s}$ \\
Floating floor + ceiling panels (living room - VH) & $0.91 \mathrm{~s}$ & $1.18 \mathrm{~s}$ \\
Floating floor + ceiling panels (dining room - VH) & $1.30 \mathrm{~s}$ & $0.91 \mathrm{~s}$ \\
Wall/ceiling panels (living room - LH) & & $0.57 \mathrm{~s}$ \\
\hline
\end{tabular}


Two independent-samples Kolmogorov-Smirnov tests were performed to check whether the noise levels' distributions ( $\mathrm{N}=768$ ) were the same across the two categories of the acoustic treatment variable. Statistically significant differences were observed for both the corridor-living room case $(D$ $=1.479, p=0.025)$ and the bedroom case $(D=2.165, p<0.001)$. Figure 7 presents the noise levels distributions in the ante and post condition, for the corridor-living room and bedroom cases, accordingly. For the former case, it can be observed that the distributions have a similar shape with a slight shift (a couple of $d B$ ) towards the "quiet", in the 40-65 dB range. For the latter, the distributions look substantially different with many levels' occurrences, shifting from the extremes (quiet and loud) to the central part of the levels' range (50-65 dB). In both cases, the distributions show some "bi-modal" patterns, with most of occurrences in the quiet or loud parts of the range. A possible explanation for this is that both types of spaces are only used in some moments of the days (and nights), thus silence is often experienced.
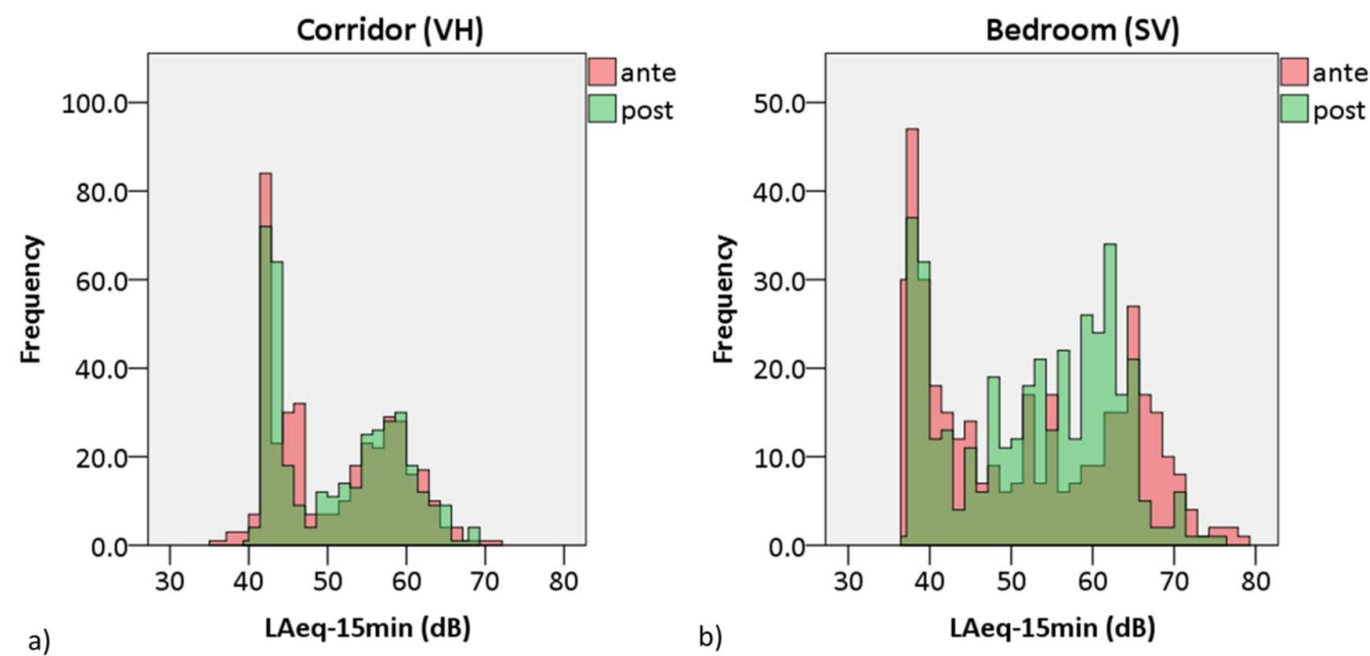

Figure 7 - Noise levels distributions for the ante and post operam conditions in a corridor in VH (a) and a bedroom in SV (b)

\section{STAFF RESPONSE TO THE ACOUSTIC INTERVENTIONS}

In Section 3, the improvements achieved through the noise mitigation interventions in the nursing homes are quantitatively described in terms of room acoustics and sound insulation metrics. However, in order to get more insights into how the effectiveness of such interventions were (or were not) actually perceived, a more qualitative approach was sought and a group interview with staff members of the nursing homes was organised. The aim was collecting staff views on the (eventually) observed benefits provided by the acoustic interventions on the daily routine of the 
facilities, and therefore to gather indirectly information on the residents' behaviours too, which are difficult to measure. This part of the study was approved by the Commission for Medical Ethics of the Faculty of Medicine and Health Sciences at Ghent University (ref: 2016/1501 granted on Dec $\left.16^{\text {th }}, 2016\right)$. Semi-structured interviewing approaches, such as group interviews and focus groups, are becoming a common method to collect data about the perception of acoustic environments or some of their components in everyday life spaces (Fiebig \& Schulte-Fortkamp, 2004; Liu \& Kang, 2016; Yilmazer \& Acun, 2018).

\subsection{Methodology for the qualitative data collection}

The present study was not only looking at the engineering side of the acoustic performance enhancement of the facilities, but also at the connected psychological effects that the deployed technical solutions could trigger. For this purpose, a feedback moment was organised through a group interview a couple of weeks after the implementation of the noise mitigation solutions in the nursing homes was finalised, to get an overview of the short-term observed effects. Seven staff members ( 2 Males, 5 Females; Age: $M=44.3, S D=7.5$; Years of service in their $\mathrm{NH}: M=15.0, S D=$ 6.9) from the five nursing homes of the project were invited to take part; there was at least one member from each nursing home, one nursing home participated with three people. Furthermore, additional feedback was gathered occasionally from individual staff members in follow-up meetings. Participants were directors, care coordinators, head nurses or occupational therapists responsible for people with dementia in the nursing homes. The rationale for participants' selection was having a group with a relatively common background, but not necessarily the same duties and responsibilities in the facilities. In particular, preference was given to the contact persons of the project and/or staff with more managerial/supervision roles. It was assumed they were likely to provide useful insights and from a broader point of view compared to bedside staff; nevertheless, they were also expected to gather insights from the perspective of the bedside professional to have informed input in the group interview. For this reasons, it seems fair to assume that controlling for personal factors (e.g., gender, age, sound preferences, working patterns, etc.) for bedside staff would not have been necessary. Participants of the focus group were not bedside staff, but rather worked in coordination roles, thus their feedback was already "mediating" the information gathered from staff in closer contact with residents and their family members.

The session took place in a meeting room of the Artevelde University College in Ghent, Belgium. One researcher coordinated the discussion asking open questions while two more researchers 
participated to support the moderator by passing small notes and/or drawing the attention to specific aspects of the discussion (e.g. highlighting certain non-verbal signs), but they didn't actively intervene in the discussion.

After verbally obtaining informed consent, the researchers described the reasons for the focus group interview; they answered any interviewees' questions, and started audio-recording the interview. The audio files were transcribed verbatim, translated in English, and then checked for data accuracy comparing with the original Dutch transcription (Park \& Lee, 2019).

The main questions asked by the researchers were: "How do you think the acoustic intervention in your nursing home performed?"; "How do you think this affects the experience of staff and residents?"; "How do you think this affects the visitors of the residents?". Participants had the opportunity to express their views and exchange ideas on a number of points. Since the questions were open-ended, participants could report their personal experiences, thoughts, and feelings using their own terms and in an unstructured fashion. The session lasted approximately 45 minutes: the researchers conducted the focus group and kept the discussion alive until they were confident that data saturation had been reached and no new concepts were emerging (Glaser, 1992).

\subsection{Main outcomes of the staff feedback}

The transcription of the group interview was coded using general concepts that could help to define what the main perceived effects of implementing the noise mitigation solutions in the nursing homes are. Since the staff members from the five facilities were interviewed simultaneously, and participants could discuss at any time about any facility, the outcomes of the interview are not reported separately, but the analysis was rather aimed at integrating them to identify common themes. Thematic analysis is becoming an increasingly important methodological approach in sound-related studies. According to this method, data collection relies on a number of questions to be asked by the researcher(s) to the participant. The transcription of the interview is considered as the raw data. English transcriptions in this case were coded manually, line by line using the interviewees' own words and immediate expressions. The first stage of data analysis is called "open coding": the researchers define the codes through conceptualised ideas. These are constantly compared with newly emerging concepts. Data collection and analysis were being carried out in parallel, thus this was an iterative process (Park \& Lee, 2019). The second stage of data analysis is called "axial coding": the researchers group the concepts with descriptive labels into categories. These are then linked to themes, which constitute the basis for the interpretation of the results. 
Table 5 reports a few examples of the abovementioned process, where some excerpts from the participants' transcriptions are coded and categorised. Categories such as "Positive effects in the room related to the acoustics", "Positive effects on the person related to the acoustics", "Positive effects on staff", and "Positive effects on visitors" were themed as "Direct Acoustic Effect (positive)". Thus, no negative direct acoustic effect emerged. Categories such as "Indirect, non-intentional positive effect on residents" and "Indirect, non-intentional positive effect on the staff" were themed as "Indirect Acoustic Effect (positive)". However, for the latter case (indirect effects), an "Indirect Acoustic Effect (negative)" was identified, which was composed of the categories "Indirect, nonintentional negative effect on the staff" and "Indirect, non-intentional negative effect on the residents". Finally the thematic analysis also suggests that a higher-order indirect effect of the acoustic intervention might also be happening in a "reinforcement" context, where staff members triangulate information with residents and visitors and positive feedback triggers a process of establishing a belief and/or encouraging a pattern of behaviour (i.e., in this case: the acoustical intervention is effective and people re-act accordingly because this belief is "convincing" and confirmed by others).

The group reported about a noticeable change after the implementation of the noise mitigation interventions: "Since the curtains have been placed, we noticed that the group and atmosphere in the living room is much calmer" was one of the quotes. The other staff members gave similar feedback: "The effects within the group of residents were very noticeable in the way that it's more enjoyable / pleasant certainly when taking into account the number of persons in the group", "The colleagues noticed a difference in their own behaviour and feelings, I'm convinced that this also influences the behaviour of the residents, and you also give this through to your residents". To some extent, the group interview participants also tried to make anticipations on long-term scenarios and expressed some concerns about the possibility of habituation effects to occur for staff, with respect to the perceived effectiveness of the acoustic intervention. More specifically, the group questioned whether the feedback was positive because the correction had just been implemented and the change was noticeable by contrast, and whether the perceived benefit provided by the intervention will stay in the future and/or be compatible with the functioning of the facility.

Overall, two main recurring themes were identified, which are: (1) Direct acoustic effect - the perceived direct effects of the interventions (i.e., those being related to the change in the acoustic environment itself); and (2) Indirect acoustic effect - the perceived indirect effects of the intervention (i.e., those not having direct acoustic implications). Direct effects were observed both 
for the persons with dementia but also for the staff. The residents seemed to be more relaxed, less agitated and nervous. Examples given included staff being more relaxed during, for instance, the moments they were washing and taking care of the personal hygiene of the residents. This had, according to them, also an additional effect on the residents who in turn became more relaxed. The staff also mentioned the big difference between the acoustically retrofitted places and other spaces of the facilities, stressing the fact that the habituation to the adaptation was very quickly accomplished. However, besides the positive comments, also some remarks were made concerning the practical aspects and the esthetical aspects such as colour, prints, coating, maintenance friendliness and recognisability for the persons with dementia. Staff stressed the need for "normalisation" of the materials and wanted to have a voice in the decisions.

In summary, Figure 8 provides a conceptual schematization of the thematic analysis of the feedback provided via the focus group after the noise mitigation interventions in the nursing homes were implemented. The perceived acoustic-related components resulted in more pleasant and quieter soundscapes and affected mainly the care givers (and the residents, as reported by them). The nonacoustic related factors connected to the interventions resulted in both positive and negative perceived effects: visual and lighting aspects were often improved, but the new acoustic elements were also sometimes perceived as obstacles to performing some tasks and/or elements requiring additional maintenance. According to the staff members' feedback, the visual innovation brought by the noise mitigation interventions would also be the most noticed by the residents' visitors.

Table 5 - Example of coding strategy for the thematic analysis: sample quotes from the focus group interview, with corresponding codes, categories and themes identified.

\begin{tabular}{|c|c|c|c|}
\hline $\begin{array}{l}\text { Examples of text fragments from the focus } \\
\text { group with professionals }\end{array}$ & Code & Category & Theme \\
\hline $\begin{array}{l}\text { "We really observed that there is less noise } \\
\text { in the room" }\end{array}$ & Less noise & $\begin{array}{l}\text { Positive effects in the } \\
\text { room related to the } \\
\text { acoustics }\end{array}$ & \multirow[t]{3}{*}{$\begin{array}{l}\text { Direct acoustic } \\
\text { effect (positive) }\end{array}$} \\
\hline $\begin{array}{l}\text { "We feel that residents become more } \\
\text { relaxed since the acoustical atmosphere is } \\
\text { quieter and less chaotic." }\end{array}$ & $\begin{array}{l}\text { Becoming more relaxed } \\
\text { because of the acoustical } \\
\text { intervention }\end{array}$ & $\begin{array}{l}\text { Positive effects on the } \\
\text { person related to the } \\
\text { acoustics }\end{array}$ & \\
\hline $\begin{array}{l}\text { "The resident in room } X \text { (who resided } \\
\text { always in her room) became more relaxed } \\
\text { after placing a curtain between the room } \\
\text { and the living room because she didn't hear }\end{array}$ & Less noise & & \\
\hline
\end{tabular}




\begin{tabular}{|c|c|c|c|}
\hline \multicolumn{3}{|l|}{$\begin{array}{l}\text { the noises that came from the living room } \\
\text { anymore." }\end{array}$} & \\
\hline $\begin{array}{l}\text { "The staff observed the differences in the } \\
\text { atmosphere within the residents' room } \\
\text { (during bathing, dressing, and meals)." }\end{array}$ & $\begin{array}{l}\text { Differences observed by } \\
\text { staff }\end{array}$ & Positive effects on staff & \\
\hline $\begin{array}{l}\text { "Visitors asked what was different in the } \\
\text { room because they experienced a quieter } \\
\text { atmosphere in the living room." }\end{array}$ & $\begin{array}{l}\text { Differences observed by } \\
\text { the visitors (unconscious). }\end{array}$ & Positive effects on visitors & \\
\hline $\begin{array}{l}\text { "Resident X (who resided in her room all the } \\
\text { time) became quieter and stopped yelling } \\
\text { because of the less chaotic noises coming } \\
\text { from the living room. That had an effect on } \\
\text { the other residents; they were less annoyed } \\
\text { by their cohabitant." }\end{array}$ & $\begin{array}{l}\text { Other residents become } \\
\text { quieter }\end{array}$ & $\begin{array}{lr}\text { Indirect, } & \text { non-intentional } \\
\text { positive effect on } \\
\text { residents }\end{array}$ & \multirow[t]{2}{*}{$\begin{array}{l}\text { Indirect acoustic } \\
\text { effect (positive) }\end{array}$} \\
\hline $\begin{array}{l}\text { "The nurses could spend more time on other } \\
\text { things, instead of trying to find a solution } \\
\text { for resident } X \text { who is very anxious and is } \\
\text { yelling a lot." }\end{array}$ & $\begin{array}{l}\text { Staff has time to do other } \\
\text { things }\end{array}$ & $\begin{array}{l}\text { Indirect, non-intentional } \\
\text { positive effect on the } \\
\text { staff. }\end{array}$ & \\
\hline $\begin{array}{l}\text { "The acoustic material in the room created } \\
\text { sometimes an unnatural sound } \\
\text { environment (to clean, no noises, hollow } \\
\text { sound...) to me." }\end{array}$ & $\begin{array}{l}\text { Acoustic material created } \\
\text { a negative feeling for the } \\
\text { staff }\end{array}$ & \multirow[t]{2}{*}{$\begin{array}{l}\text { Indirect, non-intentional } \\
\text { negative effect on the } \\
\text { staff }\end{array}$} & \multirow[t]{3}{*}{$\begin{array}{l}\text { Indirect acoustic } \\
\text { effect (negative) }\end{array}$} \\
\hline $\begin{array}{l}\text { "Applying the acoustical correction, such as } \\
\text { closing the door or closing the curtain } \\
\text { requires sometimes extra actions from the } \\
\text { staff members." }\end{array}$ & $\begin{array}{l}\text { Extra actions to apply } \\
\text { acoustical intervention }\end{array}$ & & \\
\hline $\begin{array}{l}\text { "Closing the curtain created a situation in } \\
\text { which the resident felt as being locked-in." }\end{array}$ & $\begin{array}{l}\text { Acoustic material created } \\
\text { a negative feeling for the } \\
\text { residents }\end{array}$ & $\begin{array}{l}\text { Indirect, non-intentional } \\
\text { negative effect on the } \\
\text { residents }\end{array}$ & \\
\hline $\begin{array}{l}\text { "It became clear that there is an impact on } \\
\text { the residents, on us as professionals and } \\
\text { even on the visitors. Everyone notice a } \\
\text { difference and this reinforces one-another." }\end{array}$ & $\begin{array}{l}\text { Impact on professionals, } \\
\text { visitors and residents } \\
\text { Reinforcement of the } \\
\text { three parties }\end{array}$ & $\begin{array}{l}\text { The effect of the } \\
\text { acoustical } \\
\text { accommodations is } \\
\text { reinforced by the } \\
\text { triangulation of separate } \\
\text { experience by residents, } \\
\text { staff and visitors }\end{array}$ & $\begin{array}{l}\text { Indirect acoustic } \\
\text { effect } \\
\text { (reinforcement) }\end{array}$ \\
\hline $\begin{array}{l}\text { "Yet, it needs some attention that there is } \\
\text { some kind of a habituation to the new } \\
\text { features. We will have to see whether on } \\
\text { the long run the advantages will remain } \\
\text { and we will be able to adapt to the system." }\end{array}$ & $\begin{array}{l}\text { Habituation } \\
\text { Adaptation }\end{array}$ & $\begin{array}{l}\text { All stakeholders (need to) } \\
\text { adapt }\end{array}$ & $\begin{array}{l}\text { Indirect acoustic } \\
\text { effect (adaptation) }\end{array}$ \\
\hline
\end{tabular}




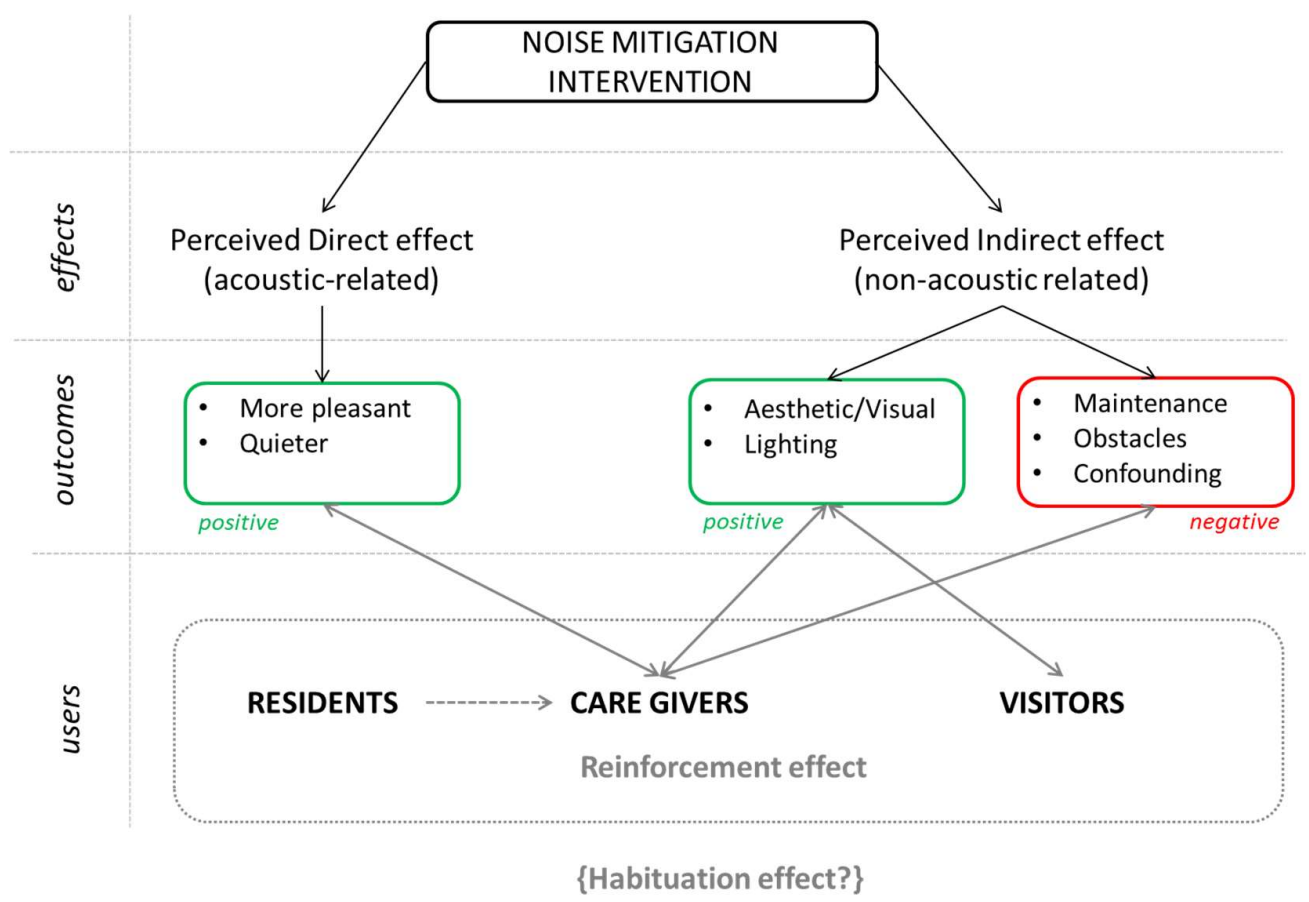

Figure 8 - Schematic representation of the outcomes of the group interview - the grey arrows represent relationships between users and outcomes; the relationship between residents and outcomes is mediated through staff observations (dashed arrow)

\section{DISCUSSION}

This study aimed at testing a mixed quantitative-qualitative approach for the management and assessment of the acoustic environment in nursing homes. The analysis of the acoustic requirements in nursing homes in several countries around the world showed an evolving normative context, where reference values for building acoustics performance metrics are changing and more factors are being taken into account to possibly satisfy a stronger drive towards the "user experience" of the space. Thus, having in mind the exploratory character of this work, some recent trends in soundscape research (i.e., qualitative approach) for this type of care facilities were considered first. Subsequently, a literature review was performed to highlight studies that investigated the acoustic environments of nursing homes using physical metrics (i.e., quantitative approach). The case study of the AcustiCare project aimed at combining these methodological approaches, by implementing acoustic correction interventions in five nursing homes in Belgium and measuring their effectiveness both objectively and subjectively.

\subsection{Noise environments in nursing homes: state of the art}

The interest for perception-oriented (i.e., soundscape-based) methodologies for the acoustic environments of nursing homes is growing in the research community, and this is confirmed by the 
increasing number of related studies in the scientific literature. However, such studies are often only qualitative in nature and not supported by physical acoustic data.

The outcomes of the literature review conducted in Section 2 reveal that there is a limited corpus of studies dealing with the characterisation of the acoustic environments in care facilities for older adults. Due to the substantial differences in measures across the retrieved studies, it was not possible to perform any statistical or quantitative meta-analysis on the data. The type of measurements deployed in those studies point out a first mismatch between what topics are of interest for the care facilities stakeholders, and what tools the normative framework is actually providing. The current (and future) standards mainly look at passive acoustic requirements of building spaces or building elements (e.g., sound insulation performance, reverberation time, etc.). On the other hand, professionals of the sector seem to be keener to monitor medium- to long-term ambient noise levels in the care facilities and investigate how these can affect the experience of the place and/or induce behavioural changes for staff and residents. Equivalent sound levels were indeed used in all the four studies considered in the literature review, even though the reference time interval differ between papers. Jerlehag et al. (2018) and Brown et al. (2016) referred to shorter time intervals ( $L_{\text {eq-1min }}$ and $L_{\text {Aeq-5min, }}$ accordingly), while Peng et al. (2018) relied on day- and nightlong background noise level (BNLs) measurements. In nursing homes, levels related to longer integration intervals are probably better used in combination with other peak level values (e.g., $\left.L_{A, p e a k, m a x}\right)$, as the comparison of the two allows for the identification of potentially disturbing events and sound sources (van Hout, Hak, Suren, \& Kort, 2014), while monitoring based on shorter time intervals alone (e.g. 1-minute levels integration) might be "too detailed" for noise events to be clearly interpretable. A 15-minute interval as proposed in Aletta et al. (2017a; 2017b) might be a sensible trade-off between the need of having a temporal resolution which is detailed enough to identify noise events occurring locally, and letting macro-scale patterns related to activities and behaviours taking place in the facility to emerge and be observable for the research and management teams.

\subsection{Combining quantitative and qualitative methods: the experience of the AcustiCare project}

Looking at the case study developed within the AcustiCare project and reported in Section 3, several points emerged from the characterization of the ante operam acoustical situation in the five nursing homes. Firstly, in terms of noise levels, highest levels were measured in living rooms, typically ranging between $55 \mathrm{~dB}$ and $60 \mathrm{~dB}$ during the day. From comparison between nursing homes, a $5 \mathrm{~dB}-$ 
difference between median levels could be observed. Secondly, the building acoustic performance was measured and compared to the target values proposed in the Belgian standard. One aspect to bear in mind is that the new standard will differentiate more between the different functions of the facilities. For airborne sound insulation, the reference values will be: $D_{A}=D_{n T, W}+C \geq 50 \mathrm{~dB}$ between bedrooms; $D_{A} \geq 38 \mathrm{~dB}$ between bedroom and corridor, and $D_{A} \geq 54 \mathrm{~dB}$ between bedroom and community room. For impact sound insulation, the reference values will be: $L_{n T, w}^{\prime} \leq 60 \mathrm{~dB}$ between bedrooms, $L_{n T, w}^{\prime} \leq 60 \mathrm{~dB}$ from corridors to bedrooms, and $L_{n T, w}^{\prime} \leq 50 \mathrm{~dB}$ from living rooms to bedrooms. Generally, acoustic comfort in (in terms of $T_{500 \mathrm{~Hz}-2 \mathrm{kHz}}$ ) and acoustic insulation between residents' rooms (in terms of $D_{n T, w}$ and $L_{n T, w}^{\prime}$ ) complied with the current standard. The current target value of $D_{n T, w}=44 \mathrm{~dB}$ was often met, with $D_{n T, w}=49.7 \mathrm{~dB}$ on average for airborne sound insulation between residents' rooms. However, the new standard requirement will be $D_{A}=50 \mathrm{~dB}$. The average $D_{A}=48.4 \mathrm{~dB}$ of the case study would not comply; although the proposed standard does allows a margin of $2 \mathrm{~dB}$ due to measurement uncertainties.

Sound insulation between corridor (and living room) and the residents' rooms was rather low, with a low average $D_{n T, w}$-value of $27.3 \mathrm{~dB}$ and high average $L_{n T, w}^{\prime}$-value of $66.9 \mathrm{~dB}$. For the former $D_{A}=$ $26.5 \mathrm{~dB}$ should be compared with the new standard requirement $D_{A}=38 \mathrm{~dB}$; thus, the requirement would not be reached. For the latter, the impact noise sound insulation between residents' rooms on the same floor was $L_{n T, w}^{\prime}=56.7 \mathrm{~dB}$ on average, thus complying (for horizontal transmission, but not for vertical transmission) with the value proposed in the new standard ( $L_{n T, w}^{\prime}=60 \mathrm{~dB}$ ). Regarding the acoustic comfort a large spread on $T_{500 \mathrm{~Hz}-2 \mathrm{kHz}}$ was seen for living rooms and corridors. While some cases complied with the target value of $0.8 \mathrm{~s}$ resp. $1.2 \mathrm{~s}$, in most cases however higher values were measured. After the installation of the technical interventions agreed with the project partners, the general acoustic performance was assessed again. Regardless of whether values were complying or not with the current (and future) standards, the comparison between measurements conducted before and after the implementations show that with relatively limited interventions it is possible to improve significantly the acoustic performance of these facilities in terms of sound insulation (i.e. room-to-room situations) and room acoustics (i.e. in-room situations) with increases of $D_{n T, w}$-values of $5 \mathrm{~dB}$ and $11 \mathrm{~dB}$ and decreases of $L_{n T, w}^{\prime}$-values of $12 \mathrm{~dB}$ and $13 \mathrm{~dB}$, and room acoustics (i.e. in-room situations) with decreases of $T_{500 \mathrm{~Hz}-2 \mathrm{kHz}}$-values ranging between $0.27 \mathrm{~s}$ and $0.75 \mathrm{~s}$ seconds. Nevertheless, other issues (e.g. leaks of the doors) are more problematic to address in a retrofitting approach. 
The comparison between the ante and post conditions of the data from the sensor nodes showed instead little effect on the average (one-week) noise levels measured in the nursing homes. However, increasing the amount of absorbing surfaces and materials in the investigated cases significantly reduced the reverberation times of those environments and, even if only to a small extent, it also reduced noise levels by possibly helping to contain sound propagation from specific sources. In particular, the curtain solution in one of the bedrooms of the nursing homes (SV) was quite effective in reducing the occurrences of moderately high sound levels (i.e. above $65 \mathrm{~dB}$ ).

Regarding the results of the qualitative data gathered via the focus group, the emergence of both acoustic and non-acoustic perceived effects induced on users by the noise mitigation interventions highlights the importance of integrating different design strategies for the quality of the space of nursing homes. This is in line with previous literature that suggests looking holistically at the environmental quality of such facilities (see, e.g.: Fleming \& Purandare, 2010; Hayne \& Fleming, 2014). Participants of the focus group interview acknowledged that acoustic interventions might be more difficult to implement in nursing homes hosted in relatively old buildings (e.g., 40+ years old) and designing facilities with good acoustics is much more convenient and cost-effective than a retrofitting approach. However, enhanced acoustics should be considered in combination with other environmental factors, as some staff members might also "resist" to the implemented acoustic interventions if these are not seen as fitting the overall strategy of the nursing home functioning. The improvement potential of better acoustics and soundscapes can be optimized when it is followed by awareness and behavioural changes in staff members.

This work presents of course some limitations. A main point is related to the generalizability of the results of the current study to other test sites and contexts. In particular, the perceived effectiveness (or lack thereof) of the acoustic correction interventions might be specific to the analysed case study. However, contribution of this work should be seen as methodological in nature, aimed at proposing a combined quantitative and qualitative approach in applications where typically only one is adopted (and more often the former, rather than the latter). It would be desirable to see more studies on the acoustics of nursing homes in the future being driven by mixed methods, as these are likely to return a more comprehensive overview of the issues at stake. In this vein, the present work was aiming more for transferability rather than generalizability (Patton, 2002) (Palinkas, Horwitz, Green, Wisdom, Duan, \& Hoagwood, 2015). The qualitative part of the data has the limitation of not taking into account a direct feedback from the residents' group, but only a mediated one (i.e., via staff members); however, this has been deemed to be acceptable in similar 
studies and similar contexts (van den Bosch, 2015). Another possible issue related to the qualitative part of the study is the timing of data collection with staff members, as this occurred shortly after the implementation of the acoustic retrofits. Individuals' adaptation and habituation effects might indeed play a role for the perception of the retrofitted acoustic environment in the nursing homes in the long term and this indeed was also mentioned during the focus group interviews. While such processes were not explicitly part of the experimental design or research questions, they are definitely worth considering since they could have significant weight in terms of perceived effectiveness.

\section{CONCLUDING REMARKS}

In general, more articulated strategies might be needed when managing their acoustic environments, rather than a one-fits-all approach. Graham (2018) reported that "acoustical separation" (i.e., physically separating residents to avoid acoustical interactions and contain noises) was a common strategy in nursing homes, to reduce personal agency and allow the institution to control the organisation of daily patterns and their corresponding acoustical environments. On the other hand, the soundscape (and more recently indoor soundscape) approach proposes an integrative process where sound sources and residents' personal agency are combined and acoustic environments are co-created taking into account both their physical and perceptual characteristics (Devos, et al., 2018). As Graham (2018) observed, "the relationship to environment includes the experience of sounds. When those sounds are meaningful and familiar, they may facilitate people's connection to self-identity and connection to the people around them."

Considering the overall results of this study, it is important to highlight that nursing homes have very peculiar functional patterns, both in terms of use of the spaces and daily routines (e.g. recurring activities and sound sources). Each nursing home is unique in its own characteristics and has to deal with a continuously changing group of users (high turnovers), for both residents and staff members. Assessing the acoustic environments of these facilities might require a multifaceted and more articulated approach than what is commonly deployed for other functional buildings, and tailored solutions will possibly have to be deployed for better soundscapes and acoustic environments. 


\section{Acknowledgements}

The AcustiCare project is supported by the Flemish Agency for Innovation and Entrepreneurship (VLAIO) under the TETRA program for applied research (grant no. HBC.2016.0089). The authors are grateful to the staff members of the nursing homes, their residents and their relatives, the acoustic consultants and companies for their participation in the project. We would like to dedicate this paper to the memory of Veronique Vandenberghe, whose enthusiasm for her work and this project will be a motivation for us all to listen and to create better care environments.

\section{REFERENCES}

Aletta, F., \& Astolfi, A. (2018). Soundscapes of buildings and built environments. Building Acoustics, 25(3), 195-197.

Aletta, F., Botteldooren, D., Thomas, P., Vander Mynsbrugge, T., De Vriendt, P., Van De Velde, D., et al. (2017). Exploring the soundscape quality of five nursing homes in Flanders (Belgium): preliminary results from the AcustiCare project. Proceedings of the Internoise 2017 Conference. Hong Kong.

Aletta, F., Botteldooren, D., Thomas, P., Vander Mynsbrugge, T., De Vriendt, P., Van de Velde, D., et al. (2017). Monitoring Sound Levels and Soundscape Quality in the Living Rooms of Nursing Homes: A Case Study in Flanders (Belgium). Applied Sciences, 7(9), 874.

Aletta, F., Vander Mynsbrugge, T., Thomas, P., Filipan, K., Botteldooren, D., Petrovic, M., et al. (2018). The relationship between noise sensitivity and soundscape appraisal of care professionals in their work environment: a case study in Nursing Homes in Flanders, Belgium. Proceedings of the Euronoise 2018 Conference. Heraklion.

Aletta, F., Vander Mynsbrugge, T., Van de Velde, D., De Vriendt, P., Thomas, P., Filipan, K., et al. (2018). Awareness of 'sound' in nursing homes: A large-scale soundscape survey in Flanders (Belgium). Building Acoustics, 25(1), 43-59.

Brown, J., Fawzi, W., Shah, A., Joyce, M., Holt, G., McCarthy, C., et al. (2016). Low stimulus environments: reducing noise levels in continuing care. BMJ Open Quality, 5, u207447.w4214.

Devos, P., Aletta, F., Vander Mynsbrugge, T., Thomas, P., Filipan, K., Petrovic, M., et al. (2018). Soundscape Design for Management of Behavioral Disorders: A Pilot Study among Nursing Home Residents with Dementia. Proceedings of the Internoise 2018 Conference. Chicago.

Devos, P., Thomas, P., Aletta, F., Vander Mynsbrugge, T., De Vriendt, P., Van de Velde, D., \& Botteldooren, D. (2019). Towards understanding healthy and supportive acoustic environments: the case of a nursing home. Proceedings of the International Conference on Acoustics ICA 2019. Aachen.

Fiebig, A., \& Schulte-Fortkamp, B. (2004). The importance of the Grounded Theory with respect to soundscape evaluation. Proceedings of the Joint CFA-DAGA Conference 2004, (pp. 349-350). Strasbourg.

Fleming, R., \& Purandare, N. (2010). Long-term care for people with dementia: environmental design guidelines. International Psychogeriatrics, 22(7), 1084-1096.

Flemish Government. (2010). Eindrapport ontwikkeling van specifieke energieprestatie-indicatoren voor rusthuizen. Brussels: Department of Welfare, Public Health and Family.

Glaser, B. G. (1992). Basics of Grounded Theory analysis. Mill Valley, USA: Sociology Press. 
Graham, M. E. (2018). Re-socialising sound: investigating sound, selfhood and intersubjectivity among people living with dementia in long-term care. Sound Studies, https://doi.org/10.1080/20551940.2018.1551051.

Hayne, M. J., \& Fleming, R. (2014). Acoustic design guidelines for dementia care facilities. Proceedings of the Internoise 2014 Conference. Melbourne.

Houben, M., Brankaert, R., Bakker, S., Kenning, G., Bongers, I., \& Eggen, B. (2019). Foregrounding Everyday Sounds in Dementia. Proceedings of the 2019 on Designing Interactive Systems Conference. San Diego.

International Organization for Standardization. (2008). ISO 3382-2:2008 Acoustics - Measurement of room acoustic parameters - Part 2: Reverberation time in ordinary rooms. Geneva: ISO.

International Organization for Standardization. (2013a). ISO 717-1:2013 Acoustics -- Rating of sound insulation in buildings and of building elements -- Part 1: Airborne sound insulation. Geneva: ISO.

International Organization for Standardization. (2013b). ISO 717-2:2013 Acoustics -- Rating of sound insulation in buildings and of building elements -- Part 2: Impact sound insulation. Geneva: ISO.

International Organization for Standardization. (2014). ISO 12913-1:2014 Acoustics - Soundscape - Part 1: Definition and conceptual framework. Geneva: ISO.

International Organization for Standardization. (2016). ISO 16283-3:2016 Acoustics - Field measurement of sound insulation in buildings and of building elements - Part 3: Façade sound insulation. Geneva: ISO.

International Organization for Standardization. (2016). ISO 1996-1:2016 Acoustics - Description, measurement and assessment of environmental noise - Part 1: Basic quantities and assessment procedures. Geneva: ISO.

International Organization for Standardization. (2017). ISO 16283-1:2014/Amd.1:2017 Acoustics - Field measurement of sound insulation in buildings and of building elements - Part 1: Airborne sound insulation AMENDMENT 1. Geneva: ISO.

International Organization for Standardization. (2018). ISO 16283-2:2018 Acoustics - Field measurement of sound insulation in buildings and of building elements - Part 2: Impact sound insulation. Geneva: ISO.

Jerlehag, C., Lee, P. J., Park, S. H., Jones, T., \& Carroll, N. (2018). Acoustic environments of patient room in a typical geriatric ward. Applied Acoustics, 133, 186-193.

Liberati, A., Altman, D. G., Tetzlaff, J., Mulrow, C., Gøtzsche, P. C., A, I. J., et al. (2009). The PRISMA Statement for Reporting Systematic Reviews and Meta-Analyses of Studies That Evaluate Health Care Interventions: Explanation and Elaboration. PLoS Medicine, 6(7), e1000100.

Liu, F., \& Kang, J. (2016). A grounded theory approach to the subjective understanding of urban soundscape in Sheffield. Cities, 50, 28-39.

Palinkas, L. A., Horwitz, S. M., Green, C. A., Wisdom, J. P., Duan, N., \& Hoagwood, K. (2015). Purposeful Sampling for Qualitative Data Collection and Analysis in Mixed Method Implementation Research. Administration and Policy in Mental Health and Mental Health Services Research, 42(5), 533-544.

Park, S. H., \& Lee, P. J. (2019). How residents in multifamily housing cope with neighbour noise: The role of attitude towards the neighbors. Journal of Community Psychology, in press, 1-17. doi:10.1002/jcop.22234

Patton, M. Q. (2002). Qualitative research and evaluation methods (3rd ed.). Thousand Oaks, CA: SAGE Publications. 
Peng, J., Zeng, Y., Zhao, L., \& Zeng, J. (2018). An investigation of acoustical environments in the elderly care facilities. Applied Acoustics, 137, 45-50.

Sanford, A. M., Orrell, M., Tolson, D., Abbatecola, A. M., Arai, H., Bauer, J. M., et al. (2015). An International Definition for "Nursing Home". Journal of the American Medical Directors Association, 16(3), 181184.

Thomas, P., Aletta, F., Filipan, K., Vander Mynsbrugge, T., De Geetere, L., Dijckmans, A., et al. (2018). Evaluation and improvement of the acoustic comfort in nursing homes: a case study in Flanders, Belgium. Proceedings of the Euronoise 2018 Conference. Heraklion.

van den Bosch, K. A. (2015). Safe and Sound: Soundscape research in special needs care. Groningen: University of Groningen.

van den Bosch, K. A., Andringa, T. C., Başkent, D., \& Vlaskamp, C. (2016). The Role of Sound in Residential Facilities for People With Profound Intellectual and Multiple Disabilities. Journal of Policy and Practice in Intellectual Disabilities, 13(1), 61-68.

van den Bosch, K. A., Andringa, T. C., Peterson, W., Ruijssenaars, W. A., \& Vlaskamp, C. (2016). A comparison of natural and non-natural soundscapes on people with severe or profound intellectual and multiple disabilities. Journal of Intellectual and Developmental Disability.

van den Bosch, K. A., Andringa, T. C., Post, W. J., Ruijssenaars, W. A., \& Vlaskamp, C. (2018). The relationship between soundscapes and challenging behavior: A small-scale intervention study in a healthcare organization for individuals with severe or profound intellectual disabilities. Building Acoustics, 25(2), 123-135.

van Hout, N. H., Hak, C. C., Suren, S., \& Kort, H. S. (2014). Acoustic measurements of sound levels in common rooms and sleeping rooms of care facilities for older adults. Gerontechnology, 13(2), 86-87.

Vander Mynsbrugge, T., Van de Velde, D., Aletta, F., Botteldooren, D., Devos, P., \& De Vriendt, P. (2018). A model of soundscape for people with dementia living in nursing homes. Proceedings of the WFOT Congress 2018. Cape Town.

Wiratha, M. S., \& Tsaih, L. (2015). Acoustic comfort in long-term care facilities based on listening impressions from normal hearing individuals. Proceedings of Meetings on Acoustics, 25, 015003.

$\mathrm{Xie}, \mathrm{H} .$, \& Kang, J. (2012). The acoustic environment of intensive care wards based on long period nocturnal measurements. Noise \& Health, 14(60), 230-236.

Xie, H., Kang, J., \& Mills, G. H. (2009). Clinical review: The impact of noise on patients' sleep and the effectiveness of noise reduction strategies in intensive care units. Critical Care, 13(2), 208.

Yilmazer, S., \& Acun, V. (2018). A grounded theory approach to assess indoor soundscape in historic religious spaces of Anatolian culture: A case study on Hacı Bayram Mosque. Building Acoustics, 25(2), 137150.

NBN S 01-400 (1977). Akoestiek - Kriteria voor de akoestische isolatie / Acoustique - Critères de l'isolation acoustique

NBN S 01-401 (1987). Akoestiek - Grenswaarden voor de geluidsniveaus om het gebrek aan comfort in gebouwen te vermijden ) Acoustique - Valeurs limites des niveaux de bruit en vue d'éviter l'inconfort dans les bâtiments

prNBN S 01-400-3 (2018). Acoustic criteria for non-residential buildings (Akoestische criteria voor nietresidentiële gebouwen - Critères acoustiques pour les bâtiments non-résidentiels) 